\title{
Unequal contribution of two paralogous centromeric histones to function the cowpea centromere
}

Takayoshi Ishii ${ }^{1} 5^{*}$, Martina Juranić2 ${ }^{2}$ Shamoni Maheshwari ${ }^{3}$, Fernanda de Oliveira Bustamante ${ }^{1,7}$, Maximilian Moritz Vogt ${ }^{1,6}$, Rigel SalinasGamboa $^{4}$, Steven Dreissig ${ }^{1}$, Nial Gursanscky², Tracy How ${ }^{2}$, Joerg Fuchs $^{1}$, Veit Schubert ${ }^{1}$, Andrew Spriggs ${ }^{2}$, Jean-Philippe Vielle-Calzada ${ }^{4}$, Luca Comai ${ }^{3}$, Anna M. G. Koltunow ${ }^{2,8}$, and Andreas Houben ${ }^{1 *}$

1 - Leibniz Institute of Plant Genetics and Crop Plant Research

Gatersleben, Corrensstraße 3, 06466 Seeland, Germany

2 - Commonwealth Scientific and Industrial Research Organisation

(CSIRO) Agriculture and Food, Urrbrae, SA 5064, Australia

3 - Plant Biology Department and Genome Center, University of

California, Davis, California, USA 95616, USA

4 - UGA Laboratorio Nacional de Genómica para la Biodiversidad

CINVESTAV, Irapuato, Mexico

5 - Arid Land Research Center (ALRC), Tottori University, 1390

Hamasaka, Tottori, 680-0001, Japan

6 - Molecular Plant Breeding, Institute of Agricultural Sciences, ETH

Zurich, 8092 Zurich, Switzerland

7 - Plant Genetics and Biotechnology Laboratory, Federal University of

Pernambuco, Recife, 50670-901, Brazil

8 - Queensland Alliance for Agriculture and Food Innovation (QAAFI), University of Queensland. St Lucia, Brisbane. 4072. Australia

*Address correspondence to T. Ishii (Ishii.T@tottori-u.ac.jp) or A. Houben (houben@ipk-gatersleben.de)

Short title: Functional characterization of cowpea CENH3s

One-sentence summary: The two paralogous centromeric histones (CENH3) of cowpea contribute unequal to the function of the centromere.

The author responsible for distribution of materials integral to the findings presented in this article in accordance with the policy described in the Instructions for Authors (www.plantcell.org) is: T. Ishii (Ishii.T@tottoriu.ac.jp). 


\section{Abstract}

The legume cowpea (Vigna unguiculata, $2 \mathrm{n}=2 \mathrm{x}=22$ ) has significant tolerance to drought and heat stress. Here we analysed and manipulated cowpea centromere-specific histone $\mathrm{H} 3$ (CENH3) genes, aiming to establish a centromere-based doubled-haploid method for use in genetic improvement of this dryland crop in future. Cowpea encodes two functional CENH3 variants (CENH3.1 and CENH3.2) and two CENH3 pseudogenes. Phylogenetic analysis suggests that gene duplication of $\mathrm{CENH} 3$ occurred independently during the speciation of $V$. unguiculata and the related $V$. mungo without a genome duplication event. Both functional cowpea $\mathrm{CENH} 3$ variants are transcribed, and the corresponding proteins are intermingled in subdomains of different types of centromere sequences in a tissue-specific manner together with the outer kinetochore protein CENPC. CENH3.2 is removed from the generative cell of mature pollen, while CENH3.1 persists. Differences between both $\mathrm{CENH} 3$ paralogs are restricted to the $\mathrm{N}$-terminus. The complete CRISPR/Cas9-based inactivation of CENH3.1 resulted in delayed vegetative growth and sterility, indicating that this variant is needed for plant development and reproduction. By contrast, CENH3.2 knockout individuals did not show obvious defects during vegetative and reproductive development, suggesting that the gene is an early stage of subfunctionalization or pseudogenization.

\section{Keywords}

CENH3, CENPC, centromere-specific DNA, evolution, CRISPR/Cas9, gene evolution 


\section{Introduction}

Cowpea (Vigna unguiculata (L.) Walp) belongs to the genus Vigna, comprising more than 200 species. Cowpea is diploid $(2 n=2 x=22)$ with a genome size of $640.6 \mathrm{Mb}$ (Lonardi et al. 2019). Wild cowpea species are pantropically distributed with highest genetic diversity observed in South Africa, indicating this region is the site of origin (Padulosi and $\mathrm{Ng}$ 1997). This herbaceous legume has a pronounced tolerance to drought and heat stress, which allows cultivation on non-irrigated land in semiarid regions (Hall 2004). Cowpea is one of the eight-grain legumes currently targeted for agronomic improvement by the Consultative Group for International Agricultural Research (CGIAR) (7th CGIAR System Council meeting: https://storage.googleapis.com/cgiarorg/2018/11/SC7B_Breeding-Initiative-1.pdf). A method to generate doubled-haploids could accelerate the breeding of new, improved, cowpea cultivars. In order to establish a haploidization method based on the manipulation of the centromere (Kalinowska et al. 2019), we analyzed the centromere composition of this species.

The centromeric regions of all cowpea chromosomes are enriched in two repetitive sequences ( $p \vee u K B 1$ and pVuKB2), and seven of the eleven chromosome pairs are additionally marked by a $455 \mathrm{bp}$ tandem repeat (Iwata-Otsubo et al. 2016; Galasso et al. 1999). As centromeric sequences are neither sufficient nor required for centromere identity (Marshall et al. 2008), we focused our analysis on the centromerespecific histone $\mathrm{H} 3$ variant $\mathrm{CENH}$, which is essential for centromere function (Allshire and Karpen 2008). In most diploid eukaryotes and flowering plant species, $\mathrm{CENH} 3$ is encoded by a single copy gene. A minority of diploid plants encode two CENH3 homologs including, Arabidopsis lyrata, Luzula nivea, Hordeum vulgare (barley), Secale cereale (rye), Pisum sativum and Lathyrus sativus species (Kawabe et al. 2006; Moraes et al. 2011; Sanei et al. 2011; Neumann et al. 2012; Neumann et al. 2015b; Evtushenko et al. 2017). The apparent persistance of two CENH3 paralogs in these species raises the possibility of subfunctionalization, where each has a distinct functional role and which can be tested by studying the effect of individual gene knockouts. A TILLING mutant of the $\beta$ CENH3 paralog in barley has no phenotype (Karimi-Ashtiyani et al. 2015). However, the barley aCENH3 paralog has not been mutated, therefore functionality could not be evaluated. In tetraploid wheat, virus induced gene silencing (RNAi) used to target both $\mathrm{CENH} 3$ types suggested that both paralogs have a functional role, however, RNAi can result in off-target and incomplete silencing effects (Yuan et al. 2015). Therefore, the functional 
investigation of duplicated CENH3 loci is best evaluated by examining the phenotype of complete CENH3 knockouts.

In this study, we identified two cowpea CENH3 variants, characterized their interaction with the protein CENPC and identified novel centromeric sequences for cowpea. Phylogenetic analyses suggested that the duplication of CENH3 occurred during or before the speciation of $V$. unguiculata. CRISPR/Cas9-based inactivation of both $\mathrm{CENH3}$ variants revealed that CENH3.1 function is required for plant development and reproduction. By contrast, CENH3.2 knockout individuals did not show obvious defects during vegetative and reproductive development, suggesting that this variant is an early stage of subfunctionalization or pseudogenization.

\section{Results}

\section{Cowpea encodes two recently evolved functional variants of $\mathrm{CENH3}$} In silico analysis of the $V$. unguiculata genomic sequence (Phytozome; https://phytozome.jgi.doe.gov/pz/portal.html) resulted in the identification of two CENH3 variants, which we named: VuCENH3.1 (Transcript ID: Vigun01g066400) and VuCENH3.2 (Transcript ID: Vigun05g172200) located on chromosomes 1 and 5, respectively. The intron-exon structure of both CENH3 genes is similar, except that the first and second exons of CENH3.2 are fused (Supplemental figure 1a). The similarity is $91 \%$ at the protein level with amino acid differences primarily evident in the $\mathrm{N}$ terminal protein domain (Supplemental figure 1b). Two pseudo genes called CENH3.3-pseudo and CENH3.4-pseudo (Transcript ID: Vigun01g066300) were also identified incomplete coding regions containing exons 2-4 and 5-7 of CENH3.1, respectively (Supplemental figure 1a). CENH3.3-pseudo is located on chromosome 1 in the promoter region of an unidentified gene (Transcript ID:

Vigun01g066200). VuCENH3.4-pseudo also encoded by chromosome 1 forms incomplete CENH3 transcripts (Transcript ID: Vigun01g066300) based on RNAseq analysis (Gursanscky et al. 2019).

To understand the evolution of $C E N H 3$ in cowpea, we analyzed the CENH3 locus in the draft genomes of legume species Cajanus cajan, Glycine max, Phaseolus vulgaris, V. angularis and $V$. radiata (Supplemental figure 2a). These analyses indicated that in G. max the duplication of CENH3 arose by whole genome duplication (Neumann et al. 2015a), however, in cowpea the increase in CENH3 copy number appears to have occurred by duplication at the original CENH3 locus independent of a whole genome duplication event. CENH3.3 and 3.4- 
pseudo appear to have arisen by tandem gene duplication and pseudogenization (Supplemental figure 2b).

In order to examine if multiple CENH3 variants exist in other accessions of cowpea and related species, $14 \mathrm{~V}$. unguiculata accessions of different origin and nine related cowpea species were examined by analyzing the sequence of RT-PCR products produced using generic CENH3 primers for Vigna species (Vigna_CENH3F and Vigna_CENH3R, Supplemental table 1,2$)$. Two variants of $C E N H 3$ were identified in all $V$. unguiculata accessions, the diploid $V$. mungo and the tetraploid $V$. reflex-pilosa. The diploid Vigna species $V$. angularis, $V$. umbellate, $V$. aconitifolia, $V$. radiata, and $V$. trilobata, and the closely related species $V$. vexillata (Takahashi et al. 2016) encode a single CENH3. BLAST analysis of publicly available genomic sequence for $V$. radiata (http://plantgenomics.snu.ac.kr/sequenceserver) and $V$. angularis (http://viggs.dna.affrc.go.jp/blast), confirmed that both species encode a single variant of $C E N H 3$. Alignment of the identified CENH3 amino acid sequences identified in the 23 surveyed Vigna species revealed differences in length in the N-terminal domain, however, the length of the histone fold domain remained conserved (Supplemental Figure 3).

CENH3 amino acid mutations in $V$. unguiculata accessions containing both CENH3 variants were also found in four positions of CENH3.1 (two in the $\mathrm{N}$-terminal tail, two in the histone fold domain) and three positions of CENH3.2 (one in the $\mathrm{N}$-terminal tail, two in the histone fold domain) (Supplemental Figure 3). Our phylogenetic analysis of Vigna CENH3s suggests that duplication of CENH3 occurred independently during or before the speciation of $V$. unguiculata and $V$. mungo (Figure 1).

\section{CENH3 variants are transcribed in a tissue-specific manner}

The relative expression levels of both functional CENH3 variants were examined in different cowpea tissue types using quantitative real-time PCR. CENH3.1 transcripts are more abundant than CENH3.2 in all tissues analyzed including early and mature anthers, developing carpels, embryos and endosperm of seeds at globular, heart and at cotyledon stages of embryogenesis, leaves, mature ovules, roots and root tips (Supplemental Figure 4a). The highest expression of CENH3.1 was found in carpel and mature ovule tissue. In addition, RNA-sequencing of laser-captured microdissected (LCM) cells allowed us to understand the CENH3.1 and CENH3.2 gene expression in reproductive cell types: the megaspore mother cell (MMC), the tetrad of haploid megaspores, 2- and 4-nuclear embryo sacs, the central cell, the egg cell, as well as the early and late microspore mother cell, the tetrad of haploid microspores, the individual microspore, and the sperm cell (Supplemental Figure 4b). With 
the exception of the microspore mother cell that showed abundant CENH3.2 expression at early stages of differentiation, the expression of CENH3.1 was higher in all other reproductive cells and stages (Supplemental Figure 4b). Transcripts of CENH3.1 were particularly abundant in the MMC, the 2-nuclear embryo sac and the egg cell.

\section{CENH3.1 and CENH3.2 are co-located in cowpea centromeres}

To determine the subcentromeric arrangement of both $\mathrm{CENH3}$ variants in cowpea we generated antibodies against VuCENH3.1 and VuCENH3.2. In addition, an antibody recognizing both variants of CENH3 (antiVuCENH3 common) was produced (Supplemental Figure 1b). Western blot analysis of nuclear proteins using the developed antibodies revealed CENH3.1 and CENH3.2 dimeric signals, suggesting homodimerization (Supplemental Figure 1c).

Chromosomes were examined by immunostaining to identify locations of CENH3.1 and CENH3.2 proteins. Structured Illumination Microscopy (SIM) analysis showed intermingling of CENH3.1 and CENH3.2 signals in centromeric subdomains of interphase nuclei (Figure 2a), in mitotic chromosomes of root cells (Figure $2 \mathrm{~b}$ ) and also in extended chromatin fibers (Figure 2c). Analyses of multiple extended chromatin fibers isolated from root nuclei indicated that cowpea centromeres comprise intermingled nucleosome clusters containing either one of the two CENH3 variants or CENH3 free nucleosomes. This is consistent with the homodimers detected by Western blotting.

Antibodies to detect cowpea CENPC were generated to provide an additional marker for active centromeres. CENPC is a conserved component of most eukaryotic centromeres that links the inner and outer (microtubule-binding) components of the kinetochore (Earnshaw 2015). CENPC co-localizes with CENH3, defining active centromere chromatin (Marques et al. 2016; Falk et al. 2015; Kato et al. 2013; Carroll et al. 2010). A single CENPC candidate (VuCENPC, Transcript ID: Vigun05g287700) was identified in the cowpea genome which aligned with CENPC sequences found in other species (Supplemental Figure 5a). VuCENPC grouped in a sister branch of CENPC sequences identified in other Vigna species in phylogenetic analyses (Supplemental Figure 5b). Immunolocalization showed that the CENPC colocalized with immunosignals specific for either $\mathrm{CENH3}$ variant in chromosomes of cowpea roots (Figure $2 \mathrm{~d}, \mathrm{e}$ ). In summary, both VuCENH3.1 and VuCENH3.2 protein variants clearly show association with centromeres verifying they are likely to play functional roles in chromosome segregation. 


\section{CENH3 localization dynamics is tissue type-dependent}

Next, the distribution of CENH3.1 and CENH3.2 immunosignals was analyzed in nuclei of sporophytic and reproductive tissues to determine the localization patterns of cowpea CENH3s in different tissues in the cowpea plant life cycle. In sporophytic, leaf and root nuclei two different localization patterns of $\mathrm{CENH} 3$ were found. A total of $65.9 \%$ of leaf nuclei showed centromeric signals for localization of both $\mathrm{CENH} 3 \mathrm{~s}$ in addition to concomitant nucleoplasmic signals (termed category I). The remaining $34.1 \%$ of leaf nuclei (termed category II) showed both CENH3s located only in centromeres (Supplemental Figure 6). By contrast, in roots, $17.6 \%$ and $82.2 \%$ of nuclei showed category I and II patterns, respectively. Importantly, the similar localization patterns of CENH3.1 and $\mathrm{CENH} 3.2$ in these different sporophytic tissue types suggest similar centromere loading of both $\mathrm{CENH} 3$ variants.

In contrast to the common behavior in somatic tissues, the two cowpea $\mathrm{CENH} 3$ s revealed differences when male and female generative tissues were analyzed.

In male meiocytes, both $\mathrm{CENH} 3$ variants were found in the centromeres during all stages of meiosis (Supplemental Figure 7). CENH3.1 and CENH3.2 localize to different subdomains of the centromeres at pachytene, metaphase I, and anaphase I chromosomes (Figure 3). By contrast, the loading dynamics of the $\mathrm{CENH} 3$ proteins differ during female meiosis. In the female meiocyte (or megaspore mother cell, $\mathrm{MMC}$ ), whereas CENH3.1 is hardly present during early stages of meiosis I (Supplemental Figure 8), CENH3 is localized in discrete subdomains at leptotene (31.7\% of meiocytes), zygotene (32.5\%) and pachytene (54.3\%) stages, but is absent from adjacent somatic cells in the developing ovule (Supplemental Figure 8). These results indicate that CENH3.2 is the predominantly loaded variant in female meiotic chromosomes.

During microgametogenesis, both $\mathrm{CENH} 3$ variants marked the centromeres of the unicellular microspore (Figure $4 a, b)$. Notably, in mature pollen, the generative nucleus displayed CENH3.1, but no CENH3.2 signals. As found in A. thaliana (Ingouff et al. 2010), the decondensed vegetative nucleus is CENH3-free (Figure 4c, d). The absence of CENPC signals confirms the loss of centromeric proteins in the vegetative nucleus of cowpea (Supplemental Figure 9). Suggesting that CENH3.1 and CENH3.2 are actively removed from the centromeres of the vegetative nucleus. Surprisingly, CENH3.2 is removed from the generative nucleus during the first pollen mitosis. Therefore, in contrast 
to the similar behavior in vegetative tissue, the two CENH3s display distinct behavior in reproductive tissue.

Both CENH3 variants co-localized in egg cell centromeres in analyses facilitated using sections of mature ovules from a transgenic cowpea line containing an egg cell specific marker driven by $A$. thaliana DD45 promoter (Table 1, Figure 5). Division of the generative cell into two sperm cells primarily occurs post-pollen tube germination in cowpea (Gursanscky et al. 2019). Following double fertilization both CENH3 variants were observed in centromeres of the immature embryo at the heart stage (Supplement Figure 10). It is possible that after fertilization of the egg cell with the CENH3.2-negative sperm, the centromeres of developing embryos contain both variants of CENH3. Alternatively, de novo loading of CENH3.2 occurs at second pollen mitosis post-pollen tube germination. The lack of correlation between transcript abundance and protein localization in both male and female meiocytes suggests that both CENH3 variants are post-transcriptionally regulated in reproductive organs.

The repeat composition differs between the centromeres of cowpea Centromeres are often enriched with specific repeats. In agreement with Iwata-Otsubo et al. (2016), pVuKB2-specific signals (Galasso et al. 1999) were found in all centromeres, while only 14 out of 22 centromeres were enriched in $455 \mathrm{bp}$ tandem repeats (Figure 6a). pVuKB2 signals were found to flank the $455 \mathrm{bp}$ tandem repeat in naturally extended pachytene chromosomes (Figure 6b). To determine whether both repeats interact with CENH3-containing nucleosomes and to identify potential additional centromeric repeats in the eight chromosomes found with poor $455 \mathrm{bp}$ repeat labelling, a ChIP-seq analysis was conducted. Two novel centromeric tandem repeats with a repeat unit length of $721 \mathrm{bp}$ and 1600 $\mathrm{bp}$, respectively, were found to interact with $\mathrm{CENH} 3$ containing nucleosomes. In addition, the $455 \mathrm{bp}$ tandem repeat (Iwata-Otsubo et al. 2016) also interacted with the CENH3 in nucleosomes thus forming part of the functional centromere. By contrast the pVuKB2 sequence (Galasso et al. 1999) did not associated with CENH3-containing nucleosomes, in line with our FISH data. Both newly identified repeats mark the eight chromosomes found with poor $455 \mathrm{bp}$ repeat labelling (Figure 7a). All three centromeric repeats with a unit length of 455,721 and $1600 \mathrm{bp}$, are composed of two to five related sub-repeats, which were named $A$ to $E$. Unit $A$ is part of all three centromeric repeats (Figure $7 b$ ), and shows similarity to Ty3/gypsy retrotransposons, which are often found in plant 
centromeres (Neumann et al. 2011). No sequence similarity was found between the sequence units $A-E$ and the pericentromeric repeat PvuKB2 (Figure 7c). In conclusion, three repeats are present in CENH3-bound DNA. The 455 bp tandem repeat is dominant in the centromeres of 7 chromosome pairs. The $721 \mathrm{bp}$ and the $1600 \mathrm{bp}$ tandem repeats are major centromere components of the remaining 4 chromosome pairs.

\section{CENH3.1 is sufficient for plant development and reproduction while CENH3.2 is unable to compensate the loss of CENH3.1}

CRISPR/Cas9-based genome editing was used to test whether both CENH3 variants are functionally required during cowpea development. Three different guide RNAs were designed to induce mutations in the CENH3 variants. One to induce mutations specifically in CENH3.1 (termed Sg3) and two to induce mutations in both, CENH3.1 and CENH3.2 (Sg4 and Sg5). We generated 19 independent transgenic lines and all were analyzed by TaqMan genotyping. In addition, nextgeneration (NGS), Sanger sequencing or immunostaining were employed for the characterization of the mutants.

Among 19 T0 plants, four lines had chimeric mutations in CENH3.1 and two out of these had additional chimeric edits in CENH3.2. We focused our analysis on the T0 line named \#5B1 (transformed with Sg5), which was mutated in CENH3.1 (8.7\% of NGS reads contained mutations) and CENH3.2 (37.1\% of NGS reads contained mutations) (Supplementary table 3). Further analysis was conducted on T1 progeny of event \#5B1. Two of 13 T1 plants (events \#5B1-12 and \#5B1-13) with chimeric mutations in CENH3.1 and biallelic mutations in CENH3.2 were found and both plants were fully fertile (Supplementary table 3). We analyzed ten T2 plants from each event \#5B1-12 and \#5B1-13, respectively and confirmed the homozygous knockout of CENH3.1 in five T2 plants. A homozygous 1-bp deletion in exon 4 led to a translational frameshift in the CENH3 alpha-N-helix. Among these 20 T2 plants, none had homozygous edits in CENH3.2, but two plants \#5B1-12.3 and \#5B1-12.4 possessed biallelic heterozygous CENH3.2 mutations. Finally, we screened for homozygous CENH3.2 mutations in T3 generation and analyzed twenty T3 plants from events \#5B1-12.3 and \#5B1-12.4 confirming that six plants were Cenh3.2 $\mathrm{KO}$ mutant plants while maintaining at least one functional CENH3.1 allele. All six mutants carried a 2-bp deletion in exon 3, which introduced a stop codon 21-bp downstream from PAM site depleting centromere targeting function of CENH3.2. Immunostaining confirmed the absence of CENH3.1 and CENH3.2 in Cenh3.1 KO T2 generation and Cenh3.2 KO T3 generation, respectively (Figure 8a). The presence of CENPC in either Cenh3 mutants suggest that both $\mathrm{CENH3}$ variants interact with CENPC. 
All Cenh3.1 KO mutants displayed retarded growth with small necrotic leaves. Flower buds were formed bud stopped development before anthesis (Figure 8b). By contrast, all Cenh3.2 KO plants grew similar to the wild type, developed normal flowers and produced normal seed set (Supplementary table 4). Hence, CENH3.1 is essential for normal plant development and CENH3.2 alone, while supporting some growth, is not sufficient for normal development. Moreover, loss of CENH3.2 had no obvious influence on plant growth and reproduction in cowpea under our growth conditions.

\section{Discussion}

\section{Unusual arrangements of CENH3 genes in Vigna}

Two CENH3 variants are present in a number of diploid plant species (e.g. A. lyrata, L. nivea, H. vulgare, S. cereale, $P$. sativum and $L$. sativus species (Kawabe et al. 2006; Moraes et al. 2011; Sanei et al. 2011; Neumann et al. 2012; Neumann et al. 2015a; Finseth et al. 2015; Evtushenko et al. 2017). In animals, multiple copies of CENH3 have been identified in e.g. Caenorhabditis elegans, C. remanei, Bovidae and Drosophila (Monen et al. 2005; Li and Huang 2008; Monen et al. 2015; Kursel and Malik 2017). In Drosophila, the Cid (CENH3) gene underwent at least four independent gene duplication events during evolution of the genus. It has been suggested that retained duplicated $\mathrm{CENH3}$ genes perform nonredundant centromeric functions (Kursel and Malik 2017).

Our analysis of CENH3 in the genus Vigna revealed that members of this clade display two alternative genomic configurations: an ancestral one involving a single gene, and one resulting from gene duplication and transposition. We identified two functional CENH3 genes in two diploid species: cowpea and $V$. mungo. In most legumes, such as $P$. vulgaris, $C$. cajan, $V$. angularis and $V$. radiata, the CENH3 locus is syntenic and single copy. A whole-genome duplication in the history of legume evolution dates to 58 Mya (duplication in Papilionoid) (Cannon et al. 2010). However, the presence of only one copy of CENH3 in P. vulgaris, $C$. cajan, $V$. angularis and $V$. radiata indicates that loss of one CENH3 gene occurred after the Papilionoid genome duplication. The presence in soybean of two CENH3 genes at the conserved ancestral position, implies a second whole-genome duplication in soybean (Shoemaker et al. 1996). African Vigna (such as cowpea) and Asian Vigna (such as $V$. angularis, $V$. radiata and $V$. mungo) diverged into different species 4.7 Mya. V. mungo, V. angularis and $V$. radiata differentiated 2.8 Mya (Kang et al. 2014). It is likely that $\sim 4.7$ to $2.8 \mathrm{Mya}$, corresponding to $V$. unguiculata speciation, the ancestral cowpea CENH3 gene on 
chromosome 10 transposed and duplicated resulting in two loci, one on chromosome 1 and the other on 5 without whole genome duplication. Gene movements could be the result of double-strand break (DBS) repair through synthesis-dependent strand annealing mainly caused by transposable element activity (Wicker et al. 2010). The class II transposons, which are the major group of classical cut-and-paste transposons, comprise $6.1 \%$ of the cowpea genome (Lonardi et al. 2019). Chromosome synteny analysis between cowpea and its close relatives $V$. angularis, $V$. radiata and $P$. vulgaris revealed that chromosome 1 and 5 display rearrangements specific to the genus Vigna (Lonardi et al. 2019). In V. angularis and V. radiata, the ancestral CENH3 locus is conserved suggesting that $\mathrm{CENH3}$ movement only occurred in some Vigna species during the rearrangement of chromosomes likely together with the activation of transposable elements. In summary, in the genus Vigna, some species contain a single copy of CENH3 while both cowpea and $V$. mungo, have duplicated and transposed genes. When such a case was discovered in Drosophila (Kursel and Malik, 2017) it was considered unusual, however, Vigna, and others have evolved two CENH3 genes. This poses the question of how duplicated gene copies evolve, and whether they subfunctionalize and are selected, and how they may eventually decay to a single gene configuration.

\section{Dynamics of CENH3 protein localization in cowpea}

We demonstrated that the transcription and centromere occupancy of both cowpea CENH3 paralogs is dynamic and varies among different tissue types. The two types of cowpea CENH3 form intermingling centromeric subdomains in sporophytic (somatic) cell types and in male gametophyte precursor cells undergoing meiosis. A similar subcentromeric organization was reported for the multiple CENH3 variants of $H$. vulgare, $P$. sativum and $L$. sativus (Ishii et al. 2015a; Neumann et al. 2016). The centromeres of these species are composed of subdomains of either CENH3 variant-containing nucleosome clusters, which, although closely juxtaposed, do not overlap significantly. Due to the restricted optical resolution, it is unclear whether these regions are composed of hetero-nucleosomes containing both CENH3 variants or represent neighbouring $\mathrm{CENH3}$ variants containing homo-nucleosomes as suggested by our Western analysis. The analysis of extended centromeric chromatin fibres revealed the interruption of CENH3-positive nucleosome clusters by clusters of nucleosomes missing CENH3. Thus, cowpea centromeric chromatin fibers seem to be interspersed by nucleosomes containing other histone $\mathrm{H} 3$ variants similarly to human and Drosophila (Blower et al. 2002; Sullivan and Karpen 2004), suggesting evolutionarily conservation of this arrangement. 
The observed centromere organization and dynamics suggests that a CENH3 variant-specific loading is followed by clustering of these nucleosomes into specific centromeric subdomains. In non-plant species, the centromere-targeting domain (CATD) is required for centromere loading of CENH3/CENPA by Scm3/HJURP chaperons (Bassett et al. 2012; Foltz et al. 2009). The CATD domains of both cowpea paralogs are almost identical suggesting that the $\mathrm{N}$-terminal tails, which differ between both CENH3s, are likely involved in the tissue-specific and CENH3 typespecific loading into centromeres.

Subfunctionalization of CENH3 variants was suggested by the expression of cowpea CENH3s during pollen development. In Arabidopsis, CENH3 is removed selectively from the vegetative cells (Karimi-Ashtiyani et al. 2015; Merai et al. 2014; Ingouff et al. 2010). As a result, in mature pollen of $A$. thaliana only the sperm nuclei contain CENH3 (Ingouff et al. 2010; Karimi-Ashtiyani et al. 2015). By contrast, the monocotyledonous pearl millet retains $\mathrm{CENH3}$ in the centromeres of both sperm and vegetative cells (Ishii et al. 2015b). In cowpea, at the end of the first pollen mitosis, both CENH3s and CENPC are actively removed from the vegetative nucleus. Unexpectedly, the cowpea CENH3.2 was selectively removed in the generative cell while CENH3.1 was retained and was present in pollen sperms. The differential behavior indicates that a selective removal mechanism recognizes CENH3.2, but not CENH3.1. Given the nearly perfect identity of the histone fold domain of the two paralogs, this implicates the $\mathrm{N}$-terminus in sub functionalization. In contrast to the behavior in pollen, the egg cell retained both CENH3 paralogs. This is the same as found in oat (Ishii et al. 2015b), but different to that described in Arabidopsis (Ingouff et al. 2010).

\section{Contribution of different CENH3 to development}

When both CENH3s were knocked out in cowpea via CRISPR/Cas9, both mutant types containing either functional variant of $\mathrm{CENH3}$ displayed vegetative growth, suggesting that both $\mathrm{CENH3}$ paralogs form functional centromeres in somatic tissue. Also, both types of CENH3s are capable of CENPC interaction. However, Cenh3.1 KO plants displayed a retarded and abnormal growth phenotype, small necrotic leaves, and incomplete flowers development that did not form seed. In contrast, Cenh3.2 KO plants showed normal growth and fertility that could not be distinguished from the wild type. Hence, CENH3.1 of cowpea is essential for normal plant growth and reproduction, while CENH3.2 is a gene likely to be undergoing early subfunctionalization. Its reduced role is consistent with a trajectory of pseudogenization. We cannot rule out, however, that CENH3.2 expression could be advantageous in growing environments 
that we did not test or that it may contribute to other properties, such as genome stability, that cannot be readily evaluated by observation of two generations. Another possibility is that the inactivation of CENH3.2 during female meiosis results in subtle abnormalities that do not cause female sterility, further cytological analysis of micro- and megasporogenesis in knockout individuals will be necessary to refine the function of CENH3.2 during cowpea reproductive development.

The results in cowpea are consistent with those of barley and indicate that one of the two CENH3 duplicates is dispensable under experimental growing conditions. After inactivation of barley $\beta C E N H 3, \alpha C E N H 3$ was sufficient for mitotic and meiotic centromere function and development was normal (Karimi-Ashtiyani et al. 2015). The possibility that both CENH3s of cowpea are subfunctionalized and contribute to development is supported by analysis in wheat aCENH3 and $\beta C E N H 3$ (Yuan et al. 2015). Virus induced gene silencing (RNAi) of aCENH3 resulted in extreme dwarfing and a weakened root system suggesting that aCENH3 is essential for plant development. Reduction of plant height and reproductive fitness caused by downregulation of $\beta C E N H 3$ suggest that $\beta C E N H 3$ perhaps plays a more specialized role during reproductive development. Our results are the first to our knowledge to leverage genome editing to understand roles of duplicate CENH3 genes.

Consequently, our knockouts are expected to entail null alleles and thus provide firm evidence on the role of individual paralogs.

\section{The DNA composition of cowpea centromeres}

Centromeres are mostly composed of one type of repeat across all chromosomes of a species, such as the a-satellite in human or the 180 bp repeat pAL1 in $A$. thaliana (Murata et al. 1994; Willard and Waye 1987). However, in diploid Solanum species, soybean, common bean and chicken, the centromeres are not equally composed and different centromeric sequences exist (Iwata et al. 2013; Gong et al. 2012; Tek et al. 2010; Shang et al. 2010). A similar situation was found in cowpea by immunoprecipitation of CENH3 nucleosomes. The centromeres of this species are composed of three different repeat types. The previously described $455 \mathrm{bp}$ tandem repeat is the major component of the centromeres of 7 chromosome pairs (Iwata-Otsubo et al. 2016). The 721 bp and 1600 bp tandem repeats, identified in this study, are the major centromeric components of the remaining 4 chromosome pairs. Repeat unit $A(215 \mathrm{bp})$ is part of all three centromeric repeats and was identified as a Ty3/gypsy retrotransposon type sequence. None of the centromere repeats of cowpea were found by BLAST analysis in other Vigna species. This suggests that the centromere repeat composition in the genus is 
changing in short evolutionary periods. It will be interesting to further elucidate the evolution of centromeric sequence diversity among different Vigna species.

In conclusion, diploid cowpea encodes two types of CENH3. Both functional $C E N H 3$ variants are transcribed and the corresponding proteins are centromere-incorporated in a tissue-specific manner.

CENH3.1 and CENH3.2 proteins form intermingling subdomains in all mitotic and meiotic centromeres examined and both CENH3s interact with the binding protein CENPC. Consistent with subfunctionalization, two proteins can show differential expression and localization in cells during plant development. In the most dramatic instance, CENH3.2 is removed from the generative cell of the pollen, while CENH3.1 persists. In the centromeres of seven chromosome pairs of cowpea, CENH3 interacts with the 455 bp tandem repeat, while in the remaining 4 chromosome pairs the centromeres contain the $721 \mathrm{bp}$ and $1600 \mathrm{bp}$ tandem repeats mainly. The centromeric repeats are composed of two to five different subunits, of which only repeat unit $A(215 \mathrm{bp})$ is part of all three centromeric repeats. This repeat unit could be classified as a Ty3/gypsy retrotransposon. Wild-type CENH3.1 is essential for normal plant growth and reproduction, while CENH3.2 is dispensable, suggesting sub-functionalization or pseudogenization of this paralog.

\section{Methods}

\section{Plant material and growing conditions}

The 24 Vigna species used in this study (Supplemental Table 1) were germinated and grown in pots $(20 \mathrm{~cm}$ diameter, $25 \mathrm{~cm}$ height) in a greenhouse $\left(16 \mathrm{~h} / 8 \mathrm{~h}\right.$ day-night cycle at $26^{\circ} \mathrm{C} / 18^{\circ} \mathrm{C}$ day-night temperature). Transgenic lines in the $V$. unguiculata cV. IT86D-1010 genetic background were grown under greenhouse conditions in pots (20 $\mathrm{cm}$ diameter, $19 \mathrm{~cm}$ height) containing Bio Gro ${ }^{\circledR}$ soil mixture (Van Schaik's Bio Gro Pty Ltd., South Australia) (12h/12h day-night cycle at $28^{\circ} \mathrm{C} / 20^{\circ} \mathrm{C}$ day-night temperature, $40 \%$ relative humidity) and a $12 \mathrm{~h} / 12 \mathrm{~h}$ day-night cycle in the Australian Plant Phenomics Facility (APPF), Adelaide.

\section{Identification of CENH3 and CENPC}

CENH3 (Vigan.09G168600) (Sakai et al. 2015; Sakai et al. 2016) of Azuki bean (Vigna angularis (Willd.) Ohwi \& Ohashi) was used for the in silico identification of cowpea CENH3 in genomic and transcriptomic data of cowpea genotype IT97K-499-35 and IT86D-1010 (Spriggs et al. 2018; Lonardi et al. 2019). Trizol-isolated RNA from young leaves were used to generate cDNA with a cDNA synthesis kit (Thermo Scientific). RT-PCR 
was performed with Vigna CENH3-specific primer pairs (Supplemental Table 2). Sequencing of cloned PCR products and amino acid alignments was conducted as described in (Ishii et al. 2015b). CENH3 sequences were submitted to the DDBJ (ID: LC490903 to LC490940).

\section{Quantitative expression analysis}

Total RNA from different tissues of cowpea (mature anther, meiotic anther, carpel, embryo at torpedo stage, leaf, ovule, root, root tip, immature seed at globular and heart stage and whole immature seed) were extracted and used for cDNA synthesis. The absence of genomic DNA was confirmed by PCR using GAPDH-specific primers (Supplemental Table 2). TaqMan-based qRT-PCR was performed in a reaction volume of $10 \mu \mathrm{l}$ containing $0.5 \mu \mathrm{l}$ of cDNA, $5 \mu \mathrm{l}$ of $2 \times$ PrimeTime $^{\circledR}$ Gene Expression Master Mix (Integrated DNA Technologies), $0.33 \mu \mathrm{l}$ (330 nM) primers, $1.25 \mu \mathrm{l}$ (125 nM) Prime Time locked nucleic acid (LNA) qPCR probes for CENH3.1 and CENH3.2 (Integrated DNA Technologies) for increased probe specificity for each gene and Ubiquitin28 probe for standardization (Eurofins) (Supplemental Table 2). PCR conditions were; $95^{\circ} \mathrm{C}$ for $5 \mathrm{~min}$, followed by 35 cycles at $95^{\circ} \mathrm{C}$ for 15 seconds and 30 seconds of $61.5^{\circ} \mathrm{C}$ using a QuantStudio ${ }^{\mathrm{TM}}$ 6 Flex Real-Time PCR System (Thermo Fisher). Three technical replicates were performed for each cDNA sample. Transcript levels of each gene were normalized to Ubiquitin28 as described in (Ishii et al. 2015a). The specificity and efficiency of all primers were determined by qRT-PCR using a dilution series of cowpea cDNA or cloned CENH3 sequences. Transcript expression patterns for CENH3 genes were also analyzed using LCM-seq datasets based on laser captured microdissection of cowpea reproductive cells as described in (Gursanscky et al. 2019). Reads were aligned against the V. unguiculata IT97K-499-35 genome using Biokanga as described (Spriggs et al. 2018; Lonardi et al. 2019) and uniquely aligned reads were counted for each gene.

\section{Identification of novel centromere repeats}

After quality and adapter trimming reads from the ChIP-seq libraries were aligned to a synthetic dimer of the 455 bp repeat using bwa ( $\mathrm{Li}$ and Durbin 2009) with default settings to estimate the efficiency of the VuCENH3 ChIP. The dataset with the greatest enrichment of the $455 \mathrm{bp}$ repeat $(29.6 \%)$ was selected and depleted of reads that aligned to the reference. The remaining reads were clustered using CDHIT-EST (Li and Godzik 2006) at 0.9 sequence identity threshold. The ChIP and input datasets were mapped to representative sequences from these clusters as contigs and DESeq(Anders and Huber 2010) analysis was performed to identify contigs enriched in the VuCENH3 ChIP. The enriched 
sequences were mapped back to the cowpea genomic contigs (IT86D_1010), of which a majority overlapped tandem repeats, with a periodicity of 721 (DDBJ ID: LC490941) and 1600-bp (DDBJ ID: LC490942).

\section{Indirect immunostaining and Western analysis}

The following peptides were used for the production of polyclonal antibodies in rabbits (VuCENH3.1: PASLKVGKKKVSRASTSTP, VUCENH3.2: ASLKASRASTSVPPSQQSP, VUCENH3 common: QQSPATRSRRRAQEEEPQE and VUCENPC:

RPVYGRIHQSLATVIGVKCISPGSDGKPTMKVKSYVSDQHKELFELASS $Y)$. LifeTein (www.lifetein.com) and Li International (www.liinternationalbio.com) performed the peptide synthesis, immunization of rabbits, and peptide affinity purification of antisera. CENH3 antibodies were directly labelled with Alexa fluor $488 \mathrm{NHS}$ ester (Thermo Fisher) or NHS-rhodamine (Thermo Fisher) as described (Maheshwari et al. 2017). Mature ovules were fixed in 1× phosphatebuffered saline (PBS) containing 4\% paraformaldehyde (PFA) under vacuum at $4{ }^{\circ} \mathrm{C}$ for $10 \mathrm{~min}$ followed by a $5 \mathrm{~h}$ fixation at $4{ }^{\circ} \mathrm{C}$ without vacuum. Fixed cowpea ovules were embedded and sectioned according to (Wu et al. 2019). For the analysis of pollen mother cells, immature anthers were fixed with $1 \times$ PBS containing 4\% PFA under vacuum at 4 ${ }^{\circ} \mathrm{C}$ for $10 \mathrm{~min}$ followed by a $30 \mathrm{~min}$ fixation at $4{ }^{\circ} \mathrm{C}$ without vacuum. The anthers were washed with ice-cold $1 \times$ PBS for 3 min two times, and digested with an enzyme cocktail composed of $1 \%(\mathrm{w} / \mathrm{v})$ pectolyase (Sigma), 0.7\% (w/v) cellulase 'ONOZUKA' R-10 (Yakult), 0.7\% cellulase (CalBioChem), and 1\% cytohelicase (Sigma) dissolved in 1x PBS for 30 min at $37^{\circ} \mathrm{C}$ in a humid chamber. Anthers were subsequently washed with ice-cold $1 \times$ PBS for 3 min two times. Excised pollen mother cells were squashed in $1 \times$ PBS between slide and coverslip. Slides were used for immunostaining after removing the coverslips. Chromosome spreads derived from root meristems and mature pollen and chromatin fibres for immunostaining were processed as described in (Maheshwari et al. 2017; Ishii et al. 2015b). Whole-mount protein immunolocalization in female meiosis was performed as previously described (Salinas-Gamboa et al. 2016). Primary antibodies were used at a dilution of 1:100. Secondary antibody was Alexa Fluor 488 (Molecular Probes) at a 1:300 dlution. After secondary antibody incubation, slides were treated with propidium iodide in $1 \times$ PBS for $20 \mathrm{~min}$, washed for $30 \mathrm{~min}$ in $1 \times$ PBS, and mounted in PROLONG medium (Molecular Probes). Serial sections were captured on a confocal laser scanning microscope (Zeiss LSM 510 META), with multitrack configuration for detecting iodide (excitation with a diode-pumped solid-state laser at $568 \mathrm{~nm}$, emission collected using a band-pass of 575 to $615 \mathrm{~nm}$ ) and Alexa 488 (excitation with an argon 
laser at $488 \mathrm{~nm}$, emission collected using a band-pass of 500 to $550 \mathrm{~nm}$ ). Laser intensity and gain were set at similar levels for all experiments. Western blotting analysis was performed as described in (KarimiAshtiyani et al. 2015).

\section{Native chromatin immunoprecipitation (ChIP-seq)}

Nuclei were isolated from roots and leaves according to (Gendrel et al. 2005) from 3 - 4 day old cowpea seedlings grown at $26^{\circ} \mathrm{C}$ in darkness. Nuclei in MNase buffer were digested with $0.5 \mathrm{gels} \mathrm{U} / \mu \mathrm{l}$ micrococcal nuclease (NEB) for $25 \mathrm{~min}$ at $37^{\circ} \mathrm{C}$. The reaction was stopped with 50 mM EDTA, and the S1 and S2 chromatin fractions were prepared as described in (Maheshwari et al. 2017). For ChIP experiments, $700 \mu \mathrm{l}$ of the combined $\mathrm{S} 1$ and $\mathrm{S} 2$ solution was adjusted to a final volume of $2 \mathrm{ml}$ using the ChIP dilution buffer $(39 \mathrm{mM} \mathrm{NaCl}, 20 \mathrm{mM}$ Tris $\mathrm{HCl} \mathrm{pH} 8.0$ and $5 \mathrm{mM}$ EDTA). $10 \mu \mathrm{g}$ of antibody was bound to Dynabeads Protein A (Invitrogen) following manufacturer guidelines at $4{ }^{\circ} \mathrm{C}$ for $4 \mathrm{~h}$. Antibodycoated Dynabeads were mixed with $2 \mathrm{ml}$ ChIP solution and incubated overnight at $4{ }^{\circ} \mathrm{C}$ using a rotating shaker. Immuno-precipitated complexes were processed accordingly (Maheshwari et al. 2017). Immunoprecipitated DNA and input samples were used for library preparation following manufacturer's recommendations (Illumina TruSeq ChIP Sample Preparation Kit \#IP-202-1012). Subsequently, prepared libraries were single-end sequenced 100 bp on Illumina HiSeq 2000. The original ChIP-seq sample data are available under study accession number PRJEB9647 at the EBI data base (http://www.ebi.ac.uk/ena/data/view/PRJEB33419).

\section{Fluorescence in situ hybridization (FISH)}

Root tips were pretreated with $2 \mathrm{mM} 8$ - hydroxyquinoline at room temperature for $4 \mathrm{~h}$. Then, the material was fixed with 6:3:1 (V/V) ethanol/chloroform/glacial acetic acid for 3 days and stored at $4{ }^{\circ} \mathrm{C}$ until use. Slide preparation and FISH was performed as described in (Ishii et al. 2010). Specific sequence in pVuKB2 (Galasso et al. 1999), 721-bp tandem and 1600-bp tandem repeats were selected and PCR labelled with tetramethyl-rhodamin-5-dUTP (Roche) (Ishii et al. 2010). In addition, cyanine $55^{\prime}$ labelled 20 nucleotide-long oligos (Operon) were used as FISH probes for 455-bp repeat (Supplemental Table 2).

\section{Microscopy}

Standard fluorescence microscopy and Structured Illumination Microscopy (3D-SIM) analysis were performed as described in (Maheshwari et al. 2017). Whole-mount immunostaining serial sections of stage 1 ovules were captured on a laser scanning confocal 
microscope (Leica), with multitrack configuration for detecting $\mathrm{PI}$ (excitation with laser at $568 \mathrm{~nm}$, emission collected using BP: 575-615 $\mathrm{nm}$ ) and Alexa 488 (excitation with Argon laser at $488 \mathrm{~nm}$, emission collected using BP: 500-550 nm). Laser intensity and gain were set at similar levels for all experiments, using negative controls to adjust them and avoid overexposure and autofluorescence. Projections of selected optical sections were generated using Photoshop.

\section{Plant transformation}

For CRISPR/Cas9-based gene editing, guide RNAs were designed with CRISPRdirect (Naito et al. 2015), cloned into pChimera and into the binary vector pCAS9-TPC (Fauser et al. 2014). Guide RNAs used Sg3: a CENH3.1-specific SgRNA CTGCGACAAGAAGTCGTAGA-PAM; Sg4 and Sg5: targeting both CENH3s GCTCAAGAAGAGGAGCCGCA-PAM, and GCAGCAGCGCCACAGACTCA-PAM, respectively. Final constructs were electroporated into the Agrobacterium tumefaciens strain AGL1 for use in cowpea stable transformation according to (Popelka et al. 2006). Transformants were selected on medium containing $2.5 \mathrm{mg} / \mathrm{L}$ Basta (Hoechst) herbicide. Shoots developing healthy roots were transferred into $90 \mathrm{~mm}$ small pots containing sterilized soil mixture (Van Schaik's Bio-Gro Pty Ltd, Australia), acclimatized in the growth room at $22^{\circ} \mathrm{C}$ with $16 \mathrm{~h}$ photoperiod for up to 4 weeks and then transferred to the glasshouse in larger pots. PCR was performed to confirm the presence of the Cas9, pat and gRNA genes with the primers listed in Supplemental Table 2. Generation of a fluorescent transgenic reporter line, which carries an egg cell-specific promoter AtDD45 was described in (Gursanscky et al. 2019).

\section{Analysis of genomic edits in cowpea transgenic lines}

DNA extracted from leaf tissue of transgenic T0 plants carrying CRISPR/Cas9 T-DNA was used for Illumina Amplicon-MiSeq DNA sequencing. Target regions spanning the Cas9/sgRNA target site of CENH3.1 and CENH3.2 genes were PCR amplified using primers listed in Supplemental Table 2. Amplicons were submitted for 150 PE sequencing on the Illumina MiSeq platform at the Australian Genome Research Facility (AGRF, Melbourne). Mutations induced at the protospacer sites were analyzed with CRISPR RGEN Tools CasAnalyzer software (Park et al. 2017). Target regions were also amplified from transgenic T1 and T2 plants and cloned into pCR ${ }^{\circledR}$-Blunt II-TOPO ${ }^{\circledR}$ vector (Invitrogen) for analysis by Sanger sequencing.

\section{TaqMan-based genotyping}

TaqMan-based genotyping of plants was performed as described in (Findlay et al. 2016). Briefly, $5 \mu$ of 2x PrimeTime® Gene Expression 
Master Mix (Integrated DNA Technologies), $0.33 \mu \mathrm{l}(330 \mathrm{nM})$ of forward and reverse primers (Supplemental Table 2), $1.25 \mu \mathrm{l}(125 \mathrm{nM}$, Supplemental Table 2) of TaqManß-Probes (Drop off probe and Reference probe), $1 \mathrm{ul}$ (50 $\mathrm{ng} / \mathrm{ul}$ genomic DNA) $1.59 \mu \mathrm{l}$ of water using the following conditions with: $95^{\circ} \mathrm{C}$ for $5 \mathrm{~min}$, followed by 35 cycles at $95^{\circ} \mathrm{C}$ for 15 seconds and 30 seconds of $69{ }^{\circ} \mathrm{C}$ (Ramp rate with $0.8^{\circ} \mathrm{C} / \mathrm{s}$ decrease the temperature) and end-read of the fluorescence and plot the fluorescence intensity with scatter chart using a QuantStudio'TM 6 Flex Real-Time PCR System (Thermo Fisher).

\section{Acknowledgements}

Vigna species seeds were kindly provided by Botanic Garden Meise in Belgium. IITA for providing IT86D-1010 and IT97K-499-35 cowpea lines for use in the research. Thanks to Natalia Bazanova, Dilrukshi Nagahatenna (CSIRO), Jana Lorenz and Sylvia Swetik (IPK) for technical assistance and maintenance of transgenic plants and Jennifer Taylor (CSIRO) for bioinformatics advice and support. Thanks to Axel Himmelbach (IPK) for Next-Generation Sequencing and Anne Fiebig (IPK) for submission of sequence data to the European Nucleotide Archive.

\section{Funding}

This work was supported by a sub-award from the CSIRO for the grant 'Capturing Heterosis for smallholders: OPP1076280' from the BMGF (USA).

Authors contributions: T.I., M.J. and A.H. designed the experiments. T.I., M. J., S.M., F.O.-M., M.V., R.S.-G., S.D., N.G., T.H., J.F., V.S., and A.S. performed the experiments. T.I., M.J., L.C., J. V.-C., A.K. and A.H. wrote the paper.

\section{References}

Allshire RC, Karpen GH (2008) Epigenetic regulation of centromeric chromatin: old dogs, new tricks? Nat Rev Genet 9 (12):923-937

Anders S, Huber W (2010) Differential expression analysis for sequence count data. Genome Biol 11 (10)

Bassett EA, DeNizio J, Barnhart-Dailey MC, Panchenko T, Sekulic N, Rogers DJ, Foltz DR, Black BE (2012) HJURP Uses Distinct CENP-A Surfaces to Recognize and to Stabilize CENP-A/Histone H4 for Centromere Assembly. Dev Cell 22 (4):749-762

Blower MD, Sullivan BA, Karpen GH (2002) Conserved organization of centromeric chromatin in flies and humans. Dev Cell 2 (3):319-330 
Cannon SB, llut D, Farmer AD, Maki SL, May GD, Singer SR, Doyle JJ (2010) Polyploidy Did Not Predate the Evolution of Nodulation in All Legumes. Plos One 5 (7):e11630. doi:10.1371/journal.pone.0011630

Carroll CW, Milks KJ, Straight AF (2010) Dual recognition of CENP-A nucleosomes is required for centromere assembly. J Cell Biol 189 (7):1143-1155

Earnshaw WC (2015) Discovering centromere proteins: from cold white hands to the $A$, B, C of CENPs. Nature reviews Molecular cell biology 16 (7):443-449. doi:10.1038/nrm4001

Evtushenko EV, Elisafenko EA, Gatzkaya SS, Lipikhina YA, Houben A, Vershinin AV (2017) Conserved molecular structure of the centromeric histone CENH3 in Secale and its phylogenetic relationships. Scientific reports 7. doi:ARTN 17628

10.1038/s41598-017-17932-8

Falk SJ, Guo LY, Sekulic N, Smoak EM, Mani T, Logsdon GA, Gupta K, Jansen LET, Van Duyne GD, Vinogradov SA, Lampson MA, Black BE (2015) CENP-C reshapes and stabilizes CENP-A nucleosomes at the centromere. Science 348 (6235):699-703

Fauser F, Schiml S, Puchta H (2014) Both CRISPR/Cas-based nucleases and nickases can be used efficiently for genome engineering in Arabidopsis thaliana. Plant J 79 (2):348-359. doi:10.1111/tpj.12554

Findlay SD, Vincent KM, Berman JR, Postovit LM (2016) A digital PCR-based method for efficient and highly specific screening of genome edited cells. PLoS One 11 (4):e0153901. doi:10.1371/journal.pone.0153901

Finseth FR, Dong Y, Saunders A, Fishman L (2015) Duplication and Adaptive Evolution of a Key Centromeric Protein in Mimulus, a Genus with Female Meiotic Drive. Mol Biol Evol 32 (10):2694-2706. doi:10.1093/molbev/msv145

Foltz DR, Jansen LET, Bailey AO, Yates JR, Bassett EA, Wood S, Black BE, Cleveland DW (2009) Centromere-Specific Assembly of CENP-A Nucleosomes Is Mediated by HJURP. Cell 137 (3):472-484

Galasso I, Harrison GE, Schmidt T, Pignone D, Heslop-Harrison JS (1999) Location of two repeated DNA sequences of Vigna unguiculata (L.) Walp. on chromosomes and extended DNA fibers by FISH. J Genet and Breed 53:215-221

Gendrel AV, Lippman Z, Martienssen R, Colot V (2005) Profiling histone modification patterns in plants using genomic tiling microarrays. Nat Methods 2 (3):213-218 Gong ZY, Wu YF, Koblizkova A, Torres GA, Wang K, lovene M, Neumann P, Zhang WL, Novak P, Buell CR, Macas J, Jiang JM (2012) Repeatless and Repeat-Based Centromeres in Potato: Implications for Centromere Evolution. Plant Cell 24 (9):3559-3574. doi:10.1105/tpc.112.100511

Gursanscky N, Marzurkiewiz D, Juranić M, Johnson SD, León G, Escobar-Guzmán R, Salinas-Gamboa R, Amasende-Morales I, Riboni M, Hand M, Spriggs A, VielleCalzada J-P, A.M.G. K (2019) Analyses of cell-type specific transcriptomes during gametogenesis and seed initiation in cowpea (Vigna unguiculata L. Walp) Submitted Hall AE (2004) Breeding for adaptation to drought and heat in cowpea. Eur J Agron 21 (4):447-454

Ingouff M, Rademacher S, Holec S, Soljlc L, Xin N, Readshaw A, Foo SH, Lahouze B, Sprunck S, Berger F (2010) Zygotic Resetting of the HISTONE 3 Variant Repertoire 
Participates in Epigenetic Reprogramming in Arabidopsis. Curr Biol 20 (23):2137-

2143. doi:10.1016/j.cub.2010.11.012

Ishii T, Karimi-Ashtiyani R, Banaei-Moghaddam AM, Schubert V, Fuchs J, Houben A

(2015a) The differential loading of two barley CENH3 variants into distinct centromeric substructures is cell type- and development-specific. Chromosome Res 23 (2):277-284. doi:10.1007/s10577-015-9466-8

Ishii T, Sunamura N, Matsumoto A, Eltayeb AE, Tsujimoto H (2015b) Preferential recruitment of the maternal centromere-specific histone $\mathrm{H} 3$ (CENH3) in oat (Avena sativa L.) x pearl millet (Pennisetum glaucum L.) hybrid embryos. Chromosome Res 23 (4):709-718. doi:10.1007/s10577-015-9477-5

Ishii T, Ueda T, Tanaka H, Tsujimoto H (2010) Chromosome elimination by wide hybridization between Triticeae or oat plant and pearl millet: pearl millet chromosome dynamics in hybrid embryo cells. Chromosome Res 18 (7):821-831. doi:10.1007/s10577-010-9158-3

Iwata-Otsubo A, Lin JY, Gill N, Jackson SA (2016) Highly distinct chromosomal structures in cowpea (Vigna unguiculata), as revealed by molecular cytogenetic analysis. Chromosome Res 24 (2):197-216. doi:10.1007/s10577-015-9515-3

Iwata A, Tek AL, Richard MMS, Abernathy B, Fonseca A, Schmutz J, Chen NWG, Thareau V, Magdelenat G, Li YP, Murata M, Pedrosa-Harand A, Geffroy V, Nagaki K, Jackson SA (2013) Identification and characterization of functional centromeres of the common bean. Plant J 76 (1):47-60

Kalinowska K, Chamas S, Unkel K, Demidov D, Lermontova I, Dresselhaus T, Kumlehn J, Dunemann F, Houben A (2019) State-of-the-art and novel developments of in vivo haploid technologies. Theor Appl Genet 132 (3):593-605. doi:10.1007/s00122-0183261-9

Kang YJ, Kim SK, Kim MY, Lestari P, Kim KH, Ha BK, Jun TH, Hwang WJ, Lee T, Lee J, Shim S, Yoon MY, Jang YE, Han KS, Taeprayoon P, Yoon N, Somta P, Tanya P, Kim KS, Gwag JG, Moon JK, Lee YH, Park BS, Bombarely A, Doyle JJ, Jackson SA, Schafleitner R, Srinives P, Varshney RK, Lee SH (2014) Genome sequence of mungbean and insights into evolution within Vigna species. Nat Commun 5

Karimi-Ashtiyani R, Ishii T, Niessen M, Stein N, Heckmann S, Gurushidze M, BanaeiMoghaddam AM, Fuchs J, Schubert V, Koch K, Weiss O, Demidov D, Schmidt K, Kumlehn J, Houben A (2015) Point mutation impairs centromeric CENH3 loading and induces haploid plants. P Natl Acad Sci USA 112 (36):11211-11216.

doi:10.1073/pnas.1504333112

Kato H, Jiang JS, Zhou BR, Rozendaal M, Feng HQ, Ghirlando R, Xiao TS, Straight AF, Bai YW (2013) A Conserved Mechanism for Centromeric Nucleosome Recognition by Centromere Protein CENP-C. Science 340 (6136):1110-1113

Kawabe A, Nasuda S, Charlesworth D (2006) Duplication of centromeric histone H3 (HTR12) gene in Arabidopsis halleri and A. lyrata, plant species with multiple centromeric satellite sequences. Genetics 174 (4):2021-2032

Kursel LE, Malik HS (2017) Recurrent Gene Duplication Leads to Diverse Repertoires of Centromeric Histones in Drosophila Species. Molecular Biology and Evolution 34 (6):1445-1462 
Lavin M, Herendeen PS, Wojciechowski MF (2005) Evolutionary rates analysis of Leguminosae implicates a rapid diversification of lineages during the tertiary. Syst Biol 54 (4):575-594

Li H, Durbin R (2009) Fast and accurate short read alignment with Burrows-Wheeler transform. Bioinformatics 25 (14):1754-1760

Li WZ, Godzik A (2006) Cd-hit: a fast program for clustering and comparing large sets of protein or nucleotide sequences. Bioinformatics 22 (13):1658-1659

Li Y, Huang JF (2008) Identification and molecular evolution of cow CENP-A gene family. Mamm Genome 19 (2):139-143. doi:10.1007/s00335-007-9083-8

Lonardi S, Munoz-Amatriain M, Liang Q, Shu S, Wanamaker SI, Lo S, Tanskanen J, Schulman AH, Zhu T, Luo MC, Alhakami H, Ounit R, Hasan AM, Verdier J, Roberts PA, Santos JRP, Ndeve A, Dolezel J, Vrana J, Hokin SA, Farmer AD, Cannon SB, Close TJ (2019) The genome of cowpea (Vigna unguiculata [L.] Walp.). Plant J. doi:10.1111/tpj.14349

Maheshwari S, Ishii T, Brown CT, Houben A, Comai L (2017) Centromere location in Arabidopsis is unaltered by extreme divergence in CENH3 protein sequence. Genome Res 27 (3):471-478. doi:10.1101/gr.214619.116

Marques A, Schubert V, Houben A, Pedrosa-Harand A (2016) Restructuring of holocentric centromeres during meiosis in the plant Rhynchospora pubera. Genetics 204 (2):555-568. doi:10.1534/genetics.116.191213

Marshall OJ, Chueh AC, Wong LH, Choo KHA (2008) Neocentromeres: New insights into centromere structure, disease development, and karyotype evolution. Am J Hum Genet 82 (2):261-282

Merai Z, Chumak N, Garcia-Aguilar M, Hsieh TF, Nishimura T, Schoft VK, Bindics J, Slusarz L, Arnoux S, Opravil S, Mechtler K, Zilberman D, Fischer RL, Tamaru H (2014) The AAA-ATPase molecular chaperone $\mathrm{Cdc48/p97} \mathrm{disassembles} \mathrm{sumoylated}$ centromeres, decondenses heterochromatin, and activates ribosomal RNA genes. $P$ Natl Acad Sci USA 111 (45):16166-16171

Monen J, Hattersley N, Muroyama A, Stevens D, Oegema K, Desai A (2015) Separase Cleaves the N-Tail of the CENP-A Related Protein CPAR-1 at the Meiosis I Metaphase-Anaphase Transition in C. elegans. Plos One 10 (4):e0125382. doi:10.1371/journal.pone.0125382

Monen J, Maddox PS, Hyndman F, Oegema K, Desai A (2005) Differential role of CENP$A$ in the segregation of holocentric $C$. elegans chromosomes during meiosis and mitosis. Nat Cell Biol 7 (12):1248-1255. doi:10.1038/ncb1331

Moraes IC, Lermontova I, Schubert I (2011) Recognition of A. thaliana centromeres by heterologous $\mathrm{CENH} 3$ requires high similarity to the endogenous protein. Plant Mol Biol 75 (3):253-261. doi:10.1007/s11103-010-9723-3

Murata M, Ogura Y, Motoyoshi F (1994) Centromeric Repetitive Sequences in Arabidopsis-Thaliana. Jpn J Genet 69 (4):361-370. doi:DOI 10.1266/jjg.69.361

Naito Y, Hino K, Bono H, Ui-Tei K (2015) CRISPRdirect: software for designing CRISPR/Cas guide RNA with reduced off-target sites. Bioinformatics 31 (7):11201123

Neumann P, Navratilova A, Koblizkova A, Kejnovsky E, Hribova E, Hobza R, Widmer A, Dolezel J, Macas J (2011) Plant centromeric retrotransposons: a structural and cytogenetic perspective. Mobile DNA-Uk 2 
Neumann P, Navratilova A, Schroeder-Reiter E, Koblizkova A, Steinbauerova V, Chocholova E, Novak P, Wanner G, Macas J (2012) Stretching the rules: monocentric chromosomes with multiple centromere domains. PLoS Genet 8 (6):e1002777. doi:10.1371/journal.pgen.1002777

\section{PGENETICS-D-12-00460 [pii]}

Neumann P, Pavlikova Z, Koblizkova A, Fukova I, Jedlickova V, Novak P, Macas J (2015a) Centromeres Off the Hook: Massive Changes in Centromere Size and Structure Following Duplication of CenH3 Gene in Fabeae Species. Mol Biol Evol 32 (7):18621879. doi:10.1093/molbev/msv070

Neumann P, Pavlikova Z, Koblizkova A, Fukova I, Jedlickova V, Novak P, Macas J (2015b) Centromeres off the hook: massive changes in centromere size and structure following duplication of $\mathrm{CenH} 3$ gene in Fabeae species. Mol Biol Evol. doi:10.1093/molbev/msv070

Neumann P, Schubert V, Fukova I, Manning JE, Houben A, Macas J (2016) Epigenetic Histone Marks of Extended Meta-Polycentric Centromeres of Lathyrus and Pisum Chromosomes. Front Plant Sci 7

Padulosi S, Ng N (1997) Origin, taxonomy, and morphology of Vigna unguiculata (L.) Walp. In: Singh BB, Mohan Raji DR, Dashiel KE (eds) Advances in cowpea research. Ibadan, Nigeria: IITA, pp 1-12

Park J, Lim K, Kim JS, Bae S (2017) Cas-analyzer: an online tool for assessing genome editing results using NGS data. Bioinformatics 33 (2):286-288. doi:10.1093/bioinformatics/btw561

Popelka JC, Gollasch S, Moore A, Molvig L, Higgins TJ (2006) Genetic transformation of cowpea (Vigna unguiculata L.) and stable transmission of the transgenes to progeny. Plant Cell Rep 25 (4):304-312. doi:10.1007/s00299-005-0053-x

Sakai H, Naito K, Ogiso-Tanaka E, Takahashi Y, Iseki K, Muto C, Satou K, Teruya K, Shiroma A, Shimoji M, Hirano T, Itoh T, Kaga A, Tomooka N (2015) The power of single molecule real-time sequencing technology in the de novo assembly of a eukaryotic genome. Sci Rep 5:16780. doi:10.1038/srep16780

Sakai H, Naito K, Takahashi Y, Sato T, Yamamoto T, Muto I, Itoh T, Tomooka N (2016) The Vigna Genome Server, 'VigGS': A Genomic Knowledge Base of the Genus Vigna Based on High-Quality, Annotated Genome Sequence of the Azuki Bean, Vigna angularis (Willd.) Ohwi \& Ohashi. Plant Cell Physiol 57 (1)

Salinas-Gamboa R, Johnson SD, Sanchez-Leon N, Koltunow AM, Vielle-Calzada JP (2016) New observations on gametogenic development and reproductive experimental tools to support seed yield improvement in cowpea [Vigna unguiculata (L.) Walp]. Plant reproduction 29 (1-2):165-177. doi:10.1007/s00497015-0273-3

Sanei M, Pickering R, Kumke K, Nasuda S, Houben A (2011) Loss of centromeric histone $\mathrm{H} 3$ (CENH3) from centromeres precedes uniparental chromosome elimination in interspecific barley hybrids. Proc Natl Acad Sci U S A 108 (33):E498-E505. doi:DOI 10.1073/pnas.1103190108

Shang WH, Hori T, Toyoda A, Kato J, Popendorf K, Sakakibara Y, Fujiyama A, Fukagawa $\mathrm{T}$ (2010) Chickens possess centromeres with both extended tandem repeats and 
short non-tandem-repetitive sequences. Genome research 20 (9):1219-1228.

doi:10.1101/gr.106245.110

Shoemaker RC, Polzin K, Labate J, Specht J, Brummer EC, Olson T, Young N, Concibido V, Wilcox J, Tamulonis JP, Kochert G, Boerma HR (1996) Genome duplication in soybean (Glycine subgenus soja). Genetics 144 (1):329-338

Spriggs A, Henderson ST, Hand ML, Johnson SD, Taylor JM, Koltunow A (2018) Assembled genomic and tissue-specific transcriptomic data resources for two genetically distinct lines of Cowpea ( Vigna unguiculata (L.) Walp). Gates Open Res 2:7. doi:10.12688/gatesopenres.12777.1

Sullivan BA, Karpen GH (2004) Centromeric chromatin exhibits a histone modification pattern that is distinct from both euchromatin and heterochromatin. Nat Struct Mol Biol 11 (11):1076-1083

Takahashi Y, Somta P, Muto C, Iseki K, Naito K, Pandiyan M, Natesan S, Tomooka N (2016) Novel Genetic Resources in the Genus Vigna Unveiled from Gene Bank Accessions. Plos One 11 (1). doi:ARTN e0147568

\subsection{1/journal.pone.0147568}

Tek AL, Kashihara K, Murata M, Nagaki K (2010) Functional centromeres in soybean include two distinct tandem repeats and a retrotransposon. Chromosome Research 18 (3):337-347. doi:10.1007/s10577-010-9119-x

Wicker T, Buchmann JP, Keller B (2010) Patching gaps in plant genomes results in gene movement and erosion of colinearity. Genome Research 20 (9):1229-1237. doi:DOI 10.1101/gr.107284.110

Willard HF, Waye JS (1987) Hierarchical Order in Chromosome-Specific Human AlphaSatellite DNA. Trends Genet 3 (7):192-198. doi:Doi 10.1016/0168-9525(87)90232-0

Wu D, Ruban A, Fuchs J, Macas J, Novak P, Vaio M, Zhou Y, Houben A (2019) Nondisjunction and unequal spindle organization accompany the drive of Aegilops speltoides B chromosomes. New Phytol. doi:10.1111/nph.15875

Yuan J, Guo X, Hu J, Lv ZL, Han FP (2015) Characterization of two CENH3 genes and their roles in wheat evolution. New Phytologist 206 (2):839-851 


\section{Legends}

Fig. 1

Phylogenetic tree of Vigna based on CENH3 amino acid sequences. Two variants of CENH3 (VuCNEH3.1 and VuCENH.2) were identified in all $V$. unguiculata accessions, diploid $V$. mungo and tetraploid species of $V$. reflexo-pilosa. Other diploid Vigna species ( $V$. angularis, $V$. umbellata, $V$. aconitifolia, $V$. radiata, and $V$. trilobata and $V$. vexillata) encode a single CENH3.

Fig. 2

The organization of cowpea centromere analyzed by indirect immunostaining and Structured Illumination Microscopy (SIM) in root cells. Both CENH3.1 (green) and CENH3.2 (red) occupy distinct but intermingled nucleosome domains at centromeres in interphase nuclei (a), prometaphase chromosomes (b), and extended chromatin fibres (c). CENH3.1 (red) and CENH3.2 (red) colocalize with CENPC (green) at the centromeres of prometaphase chromosomes ( $d$ and $e$ ). Further enlarged centromere regions shown below are indicated ( $a, b, d$ and $e)$.

Fig. 3

The organization of cowpea centromeres during male meiosis analyzed by indirect immunostaining and Structured Illumination Microscopy (SIM). Both CENH3.1 (green) and CENH3.2 (red) occupy different subdomains of the centromeres at pachytene (a), metaphase I (b) and anaphase I (c) of pollen mother cells. Further enlarged centromere regions of pachytene chromosomes are shown below.

Fig. 4

The organization of cowpea centromeres during microgametogenesis. CENH3.1 (green) and CENH3.2 (red) localize in the centromeres of a early-stage mononucleate pollen ( $a$ and $b$ ). Further enlarged nuclei are shown as inserts. In mature binucleate pollen ( $c$ and $d$ ), the vegetative nucleus shows no centromeric CENH3.1 (green) and CENH3.2 (red). Centromeric CENH3.1 (green) localizes in the generative nucleus of mature pollen (c), while CENH3.2 (red) does not (d) suggesting specific removal.

Fig. 5

Tissue section of an isolated mature ovule revealing the organization of cowpea centromeres in the egg cell. Both CENH3.1 (green) and CENH3.2 (red) localize at centromeres of the egg cell. The egg cell was identified with an egg cell-specific fluorescence marker (blue), which is 
driven by the $A$. thaliana DD45 promoter. A further enlarged egg cell region is indicated in the left picture (tissue section of a mature ovule).

\section{Fig. 6}

Sequence composition of cowpea centromeres in mitotic (a) and meiotic (b) cells determined by FISH. 14 out of 22 centromeres are enriched in the 455 bp (green) tandem repeat and all centromeres contain the pVuKB2 (red) tandem repeat (a). The position of functional centromeres was confirmed by cowpea CENH3 immunostaining (magenta) (a). pVuKB2 signals (red) are flanked by 455 bp tandem repeats (green) in naturally extended pachytene chromosomes (b). Further enlarged centromere regions are shown as inserts in merged pictures.

\section{Fig. 7}

Characterization of novel centromeric tandem repeats of cowpea. Mitotic metaphase chromosomes after FISH with 721 bp (green), 1600 bp (red) and $455 \mathrm{bp}$ (red) tandem repeat-specific probes (a). Schematic illustration of the repeat unit (units $A-E$ ) organization of $455 \mathrm{bp}, 721 \mathrm{bp}$ and 1600 bp centromeric tandem repeats of cowpea (b). Phylogenetic tree based on the DNA sequences of the tandem repeat units $A$ - $E$ and pVuKB2 (c).

Fig. 8

Characterization of Cenh3.1 and Cenh3.2 KO plants of cowpea induced by CRISPR/Cas9 based genome editing. Immunostaining of isolated nuclei from Cenh3.1 and Cenh3.2 KO plants with anti-CENH3.1 (green), anti-CENH3.2 (red) and anti-CENPC (green) antibodies (a). Plant growth phenotype of Cenh3.1, Cenh3.2 KO and wild-type plants (b). Note the retarded growth of Cenh3.1 KO plants.

\section{Supplementary information}

Fig. S1

Schematic illustration of the cowpea CENH3 gene exon and intron structure (a). Alignment of CENH3.1 and CENH3.2 amino acid sequences. Green, red and black boxes indicate the position of the peptides used for the generation of CENH3.1, CENH3.2 and CENH3 common antibody, respectively (b). Western blot analysis of cowpea nuclear proteins with CENH3.1-, CENH3.2- and histone H3-specific antibodies. Different loading amounts of nuclear proteins are indicated $(30-3.75 \mu l)(d)$.

Fig. S2 
Phylogenetic tree based on the CENH3 amino acid sequence, with a scheme of the chromosomal CENH3 gene locus on the right of each species. Genome duplication events and node ages are based on (Lavin et al. 2005; Cannon et al. 2010; Kang et al. 2014) (a). Schemata of possible mechanism of CENH3 duplication in cowpea genome (b). Blue arrows indicate $\mathrm{CENH} 3$ gene locus and nearby genes indicated by different colours as A: Rhodanese-like domain-containing protein, B: WRKY transcriptional factor, C: unknown (exosome complex exonuclease), D: unknown, E: calcium-dependent lipid-binding domaincontained protein, $\mathrm{F}$ : $60 \mathrm{~S}$ ribosomal protein $\mathrm{L} 18 \mathrm{~A}$, respectively.

Fig. S3

Diversity of CENH3 in Vigna species. Multiple alignments of CENH3 proteins from different cowpea accessions ( $V$. unguiculata -Cameroon, China, -Congo, -India, -IT86D-1010, -IT97K-499-35 and -USA), different subspecies of $V$. unguiculata (Alba, Biflora, Baoulensis, Pawekiae, Sesquipedalis, Spontanea, and Stenophylla), different diploid Vigna species ( $V$. aconitifolia, $V$. angularis, $V$. mungo, $V$. radiata, $V$.trilobata, $V$. umbellate and $V$. vexillata), and tetraploid Vigna species ( $V$. reflexopilosa var glabra and $V$. reflexo-pilosa var. reflexo-pilosa). Conserved CENH3 domains are indicated with red-boxes.

Fig. S4

Gene expression patterns of CENH3.1 and CENH3.2 in different tissue and cell types of cowpea. qRT-PCR analysis using RNA isolated from different tissues of cowpea (a). RNA-sequencing using RNA isolated from laser capture microdissected cell types of cowpea (b). Leaf, MMCmegaspore mother cell, fTET-female tetrads, ES2n-embryo sac (2 nuclei), ES4n-embryo sac (4 nuclei), CenC-central cell, egg, PMC.E-early pollen mother cell, PMC.L-late pollen mother cell, mTET-male tetrads, MICmicrospore, sperm.

Fig. S5

Identification of cowpea CENPC. Alignment of partial CENPC proteins of A. thaliana, G. $\max , M$. truncatula, $V$. angularis, $V$. radiata and $V$. unguiculata (a). Phylogenetic tree based on the full length CENPC proteins of $A$. thaliana, G. max, H. vulgale, M. truncatula, S. bicolor, $V$. angularis, $V$. radiata and $V$. unguiculata.

Fig. S6

Distribution of CENH3.1 and CENH3.2 immunosignals in isolated nuclei from leaf and root tissues of cowpea. Two categories are determined 
based on the configurations of CENH3 signals (a). Category I:

Centromeric CENH3.1 and CENH3.2 signals colocalize and nuclei reveal disperse immunosignals. Category II: Centromeric CENH3.1 and CENH3.2 signals colocalize without dispersing signals. Typical examples are shown in (a). Quantification of categorized leaf $(n=208)$ and root $(n=210)$ nuclei (b). Black bar: leaf nuclei, grey bar: root nuclei.

Fig. S7

Centromeric CENH3.1 and CENH3.2 colocalize during all stages of male meiosis in cowpea. Distribution of CENH3.1 (green) and CENH3.2 (red) are shown in pachytene, diakinesis, anaphase I, prophase II and tetrad cells.

Fig. S8

Distribution of CENH3.1 and CENH3.2 during female meiosis of cowpea tissue sections. CENH3.2 immunostaining signals (green) at leptotene, zygotene and pachytene (a). Nuclei were counterstained with propidium iodide (red). Frequency of observed CENH3.1 and CENH3.2 signals in leptotene, zygotene and pachytene cells (b). Bars equal $10 \mu \mathrm{m}$.

Fig. S9

The generative nucleus of mature cowpea pollen shows colocalizing CENH3.1 (red) and CENPC (green)-specific immunosignals. The vegetative nucleus is free of centromeric immunomarks.

Fig. $S 10$

The centromeres of embryonic cells at early heart stage contain CENH3.1 and CENH3.2. CENH3.1 (green) and CENH3.2 (red) immunosignals colocalize in interphase (a) and prometaphase (b) cells. Structured Illumination Microscopy by SIM shows that both CENH3 variants occupy different centromeric subdomains (further enlarged inserts). 
Fig. 1

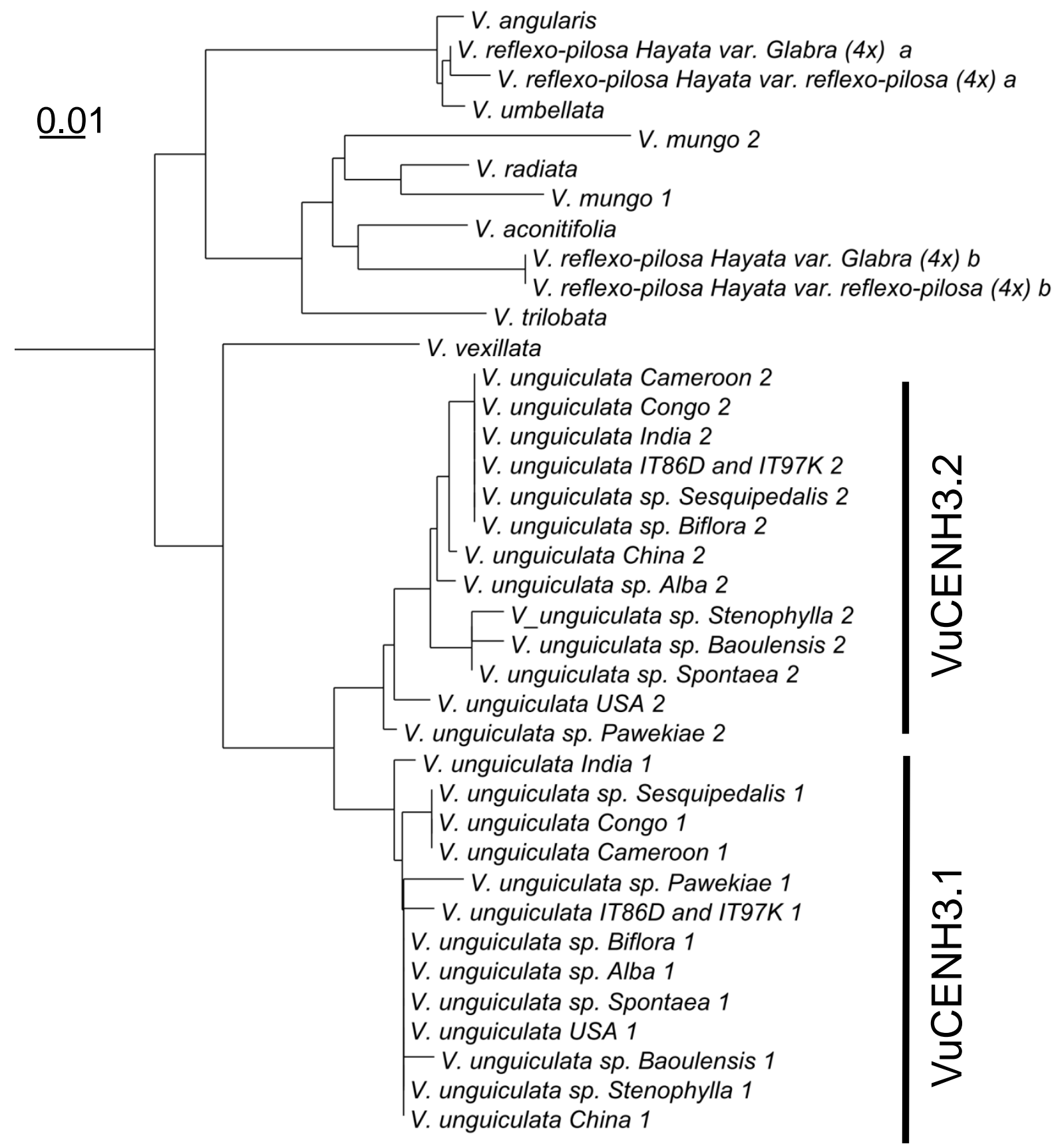


Fig. 2

(which was not certified by neer review) is the author/funder All riahts reserved No reuse allowed without permission.

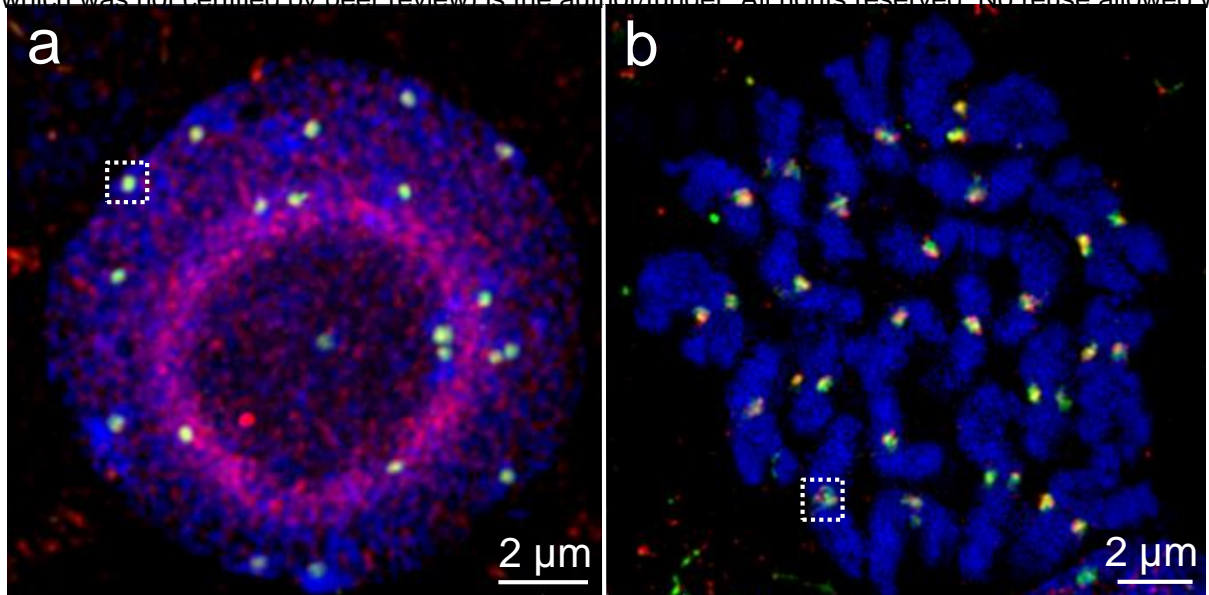

\begin{tabular}{|r|r|r|r|r|r|}
\hline Merge & CENH3.1 & CENH3.2 & Merge & CENH3.1 & CENH3.2 \\
& & $0.2 \mu \mathrm{m}$ & & & \\
\hline
\end{tabular}

C CENH3.1 CENH3.2

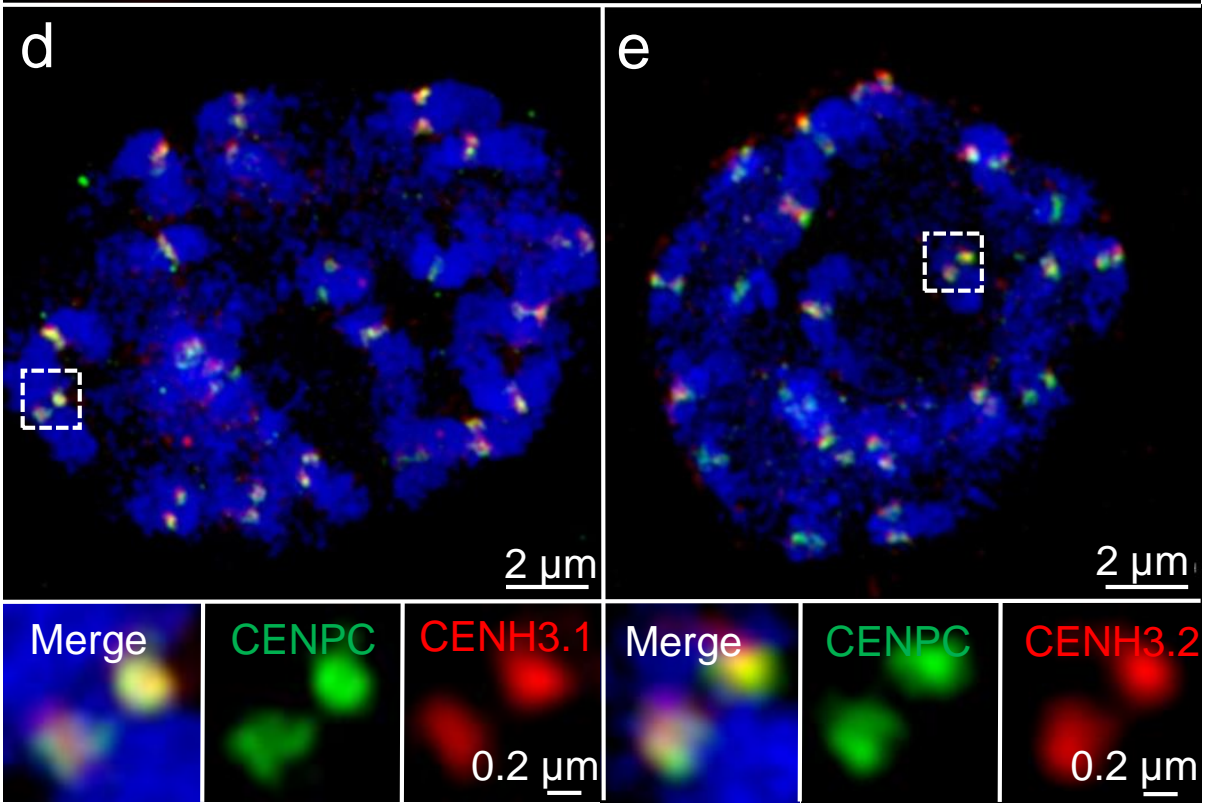


Fig. 3

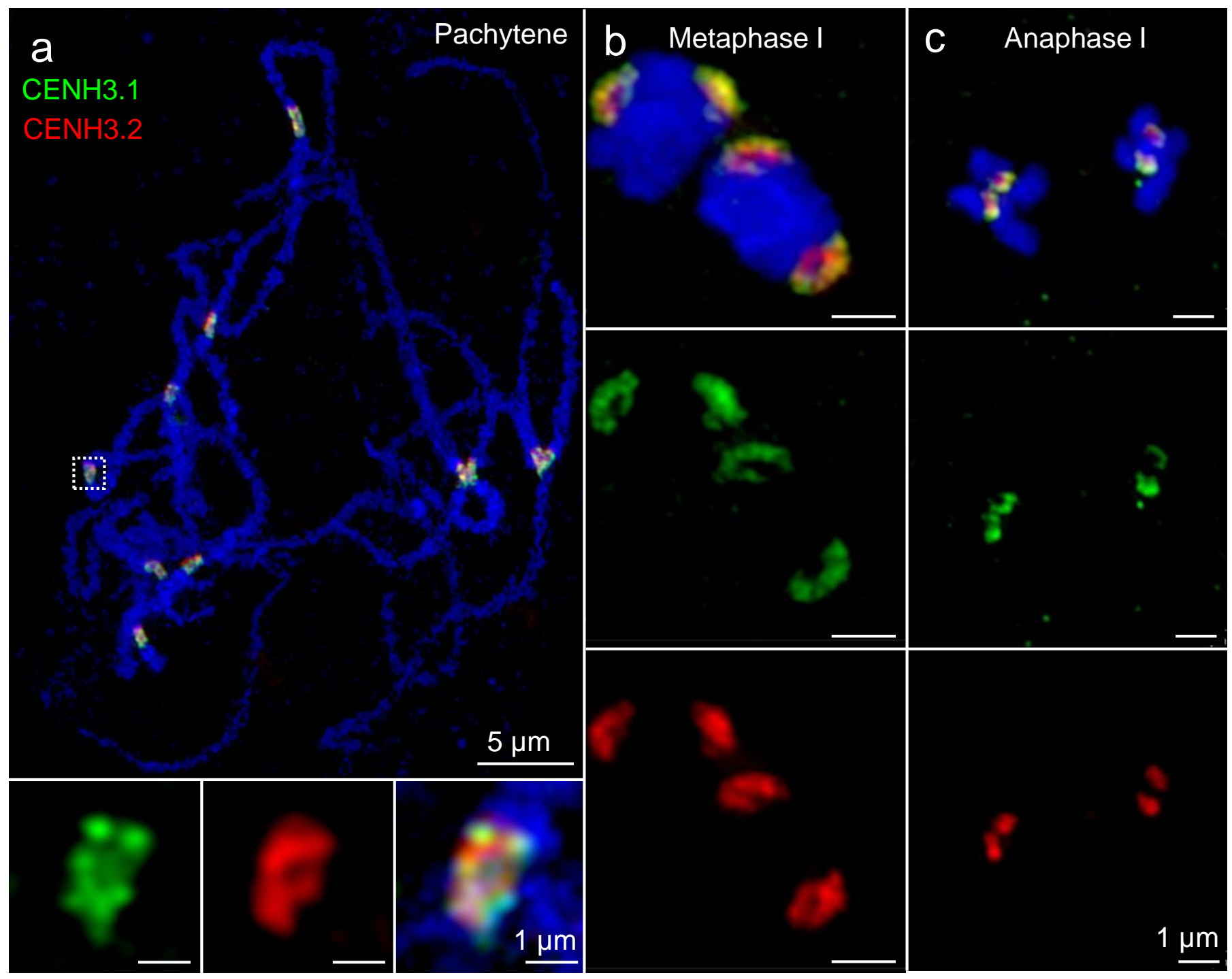


Fig. 4

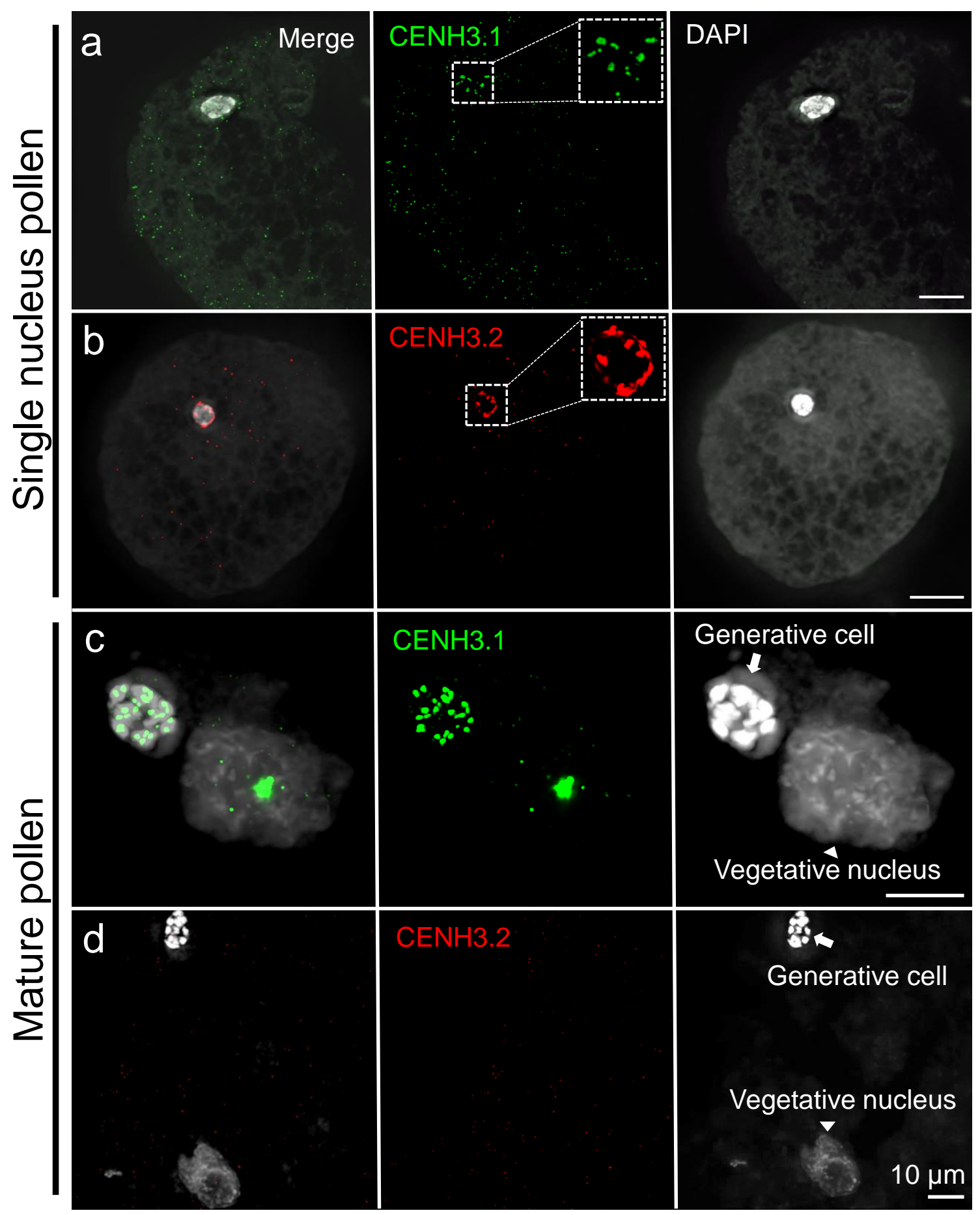


Fig. 5

(which was not certified by peer review) is the author/funder. All rights reserved. No reuse allowed without permission.

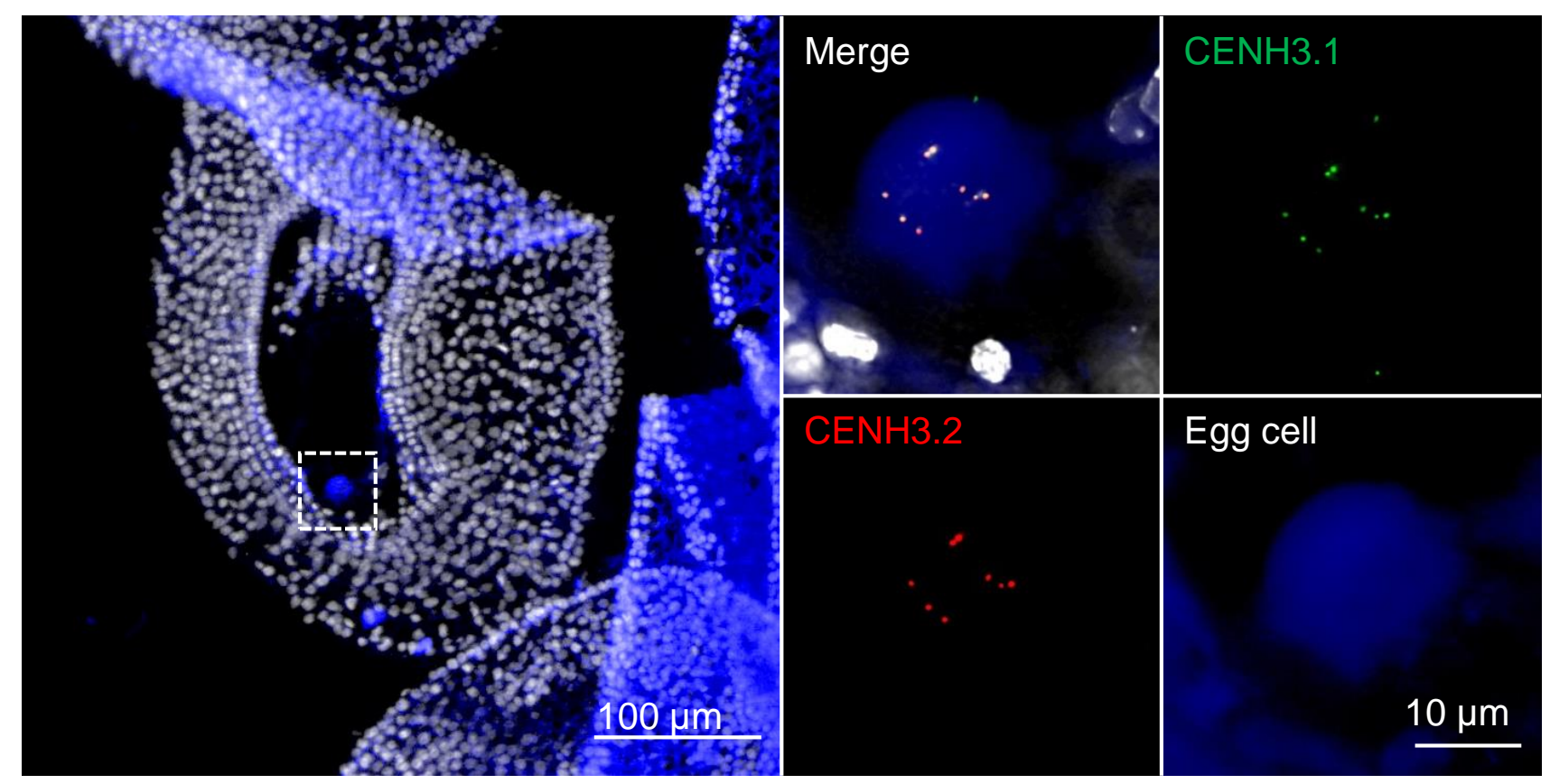


Fig. 6

(which was not certified by peer review) is the author/funder. All rights reserved. No reuse allowed without permission.

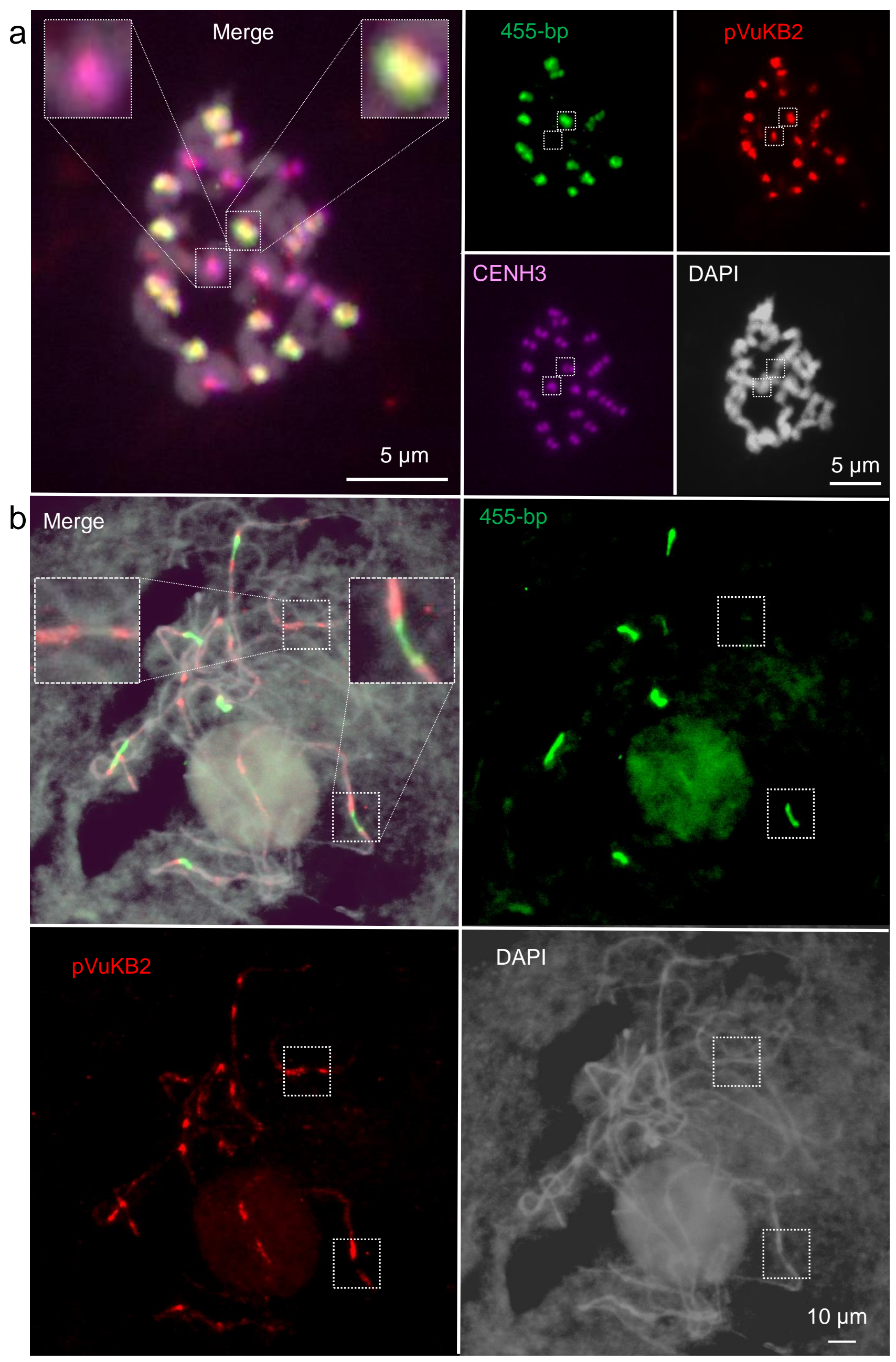


Fig. 7

(which was not certified by peer review) is the author/funder. All rights reserved. No reuse allowed without permission.

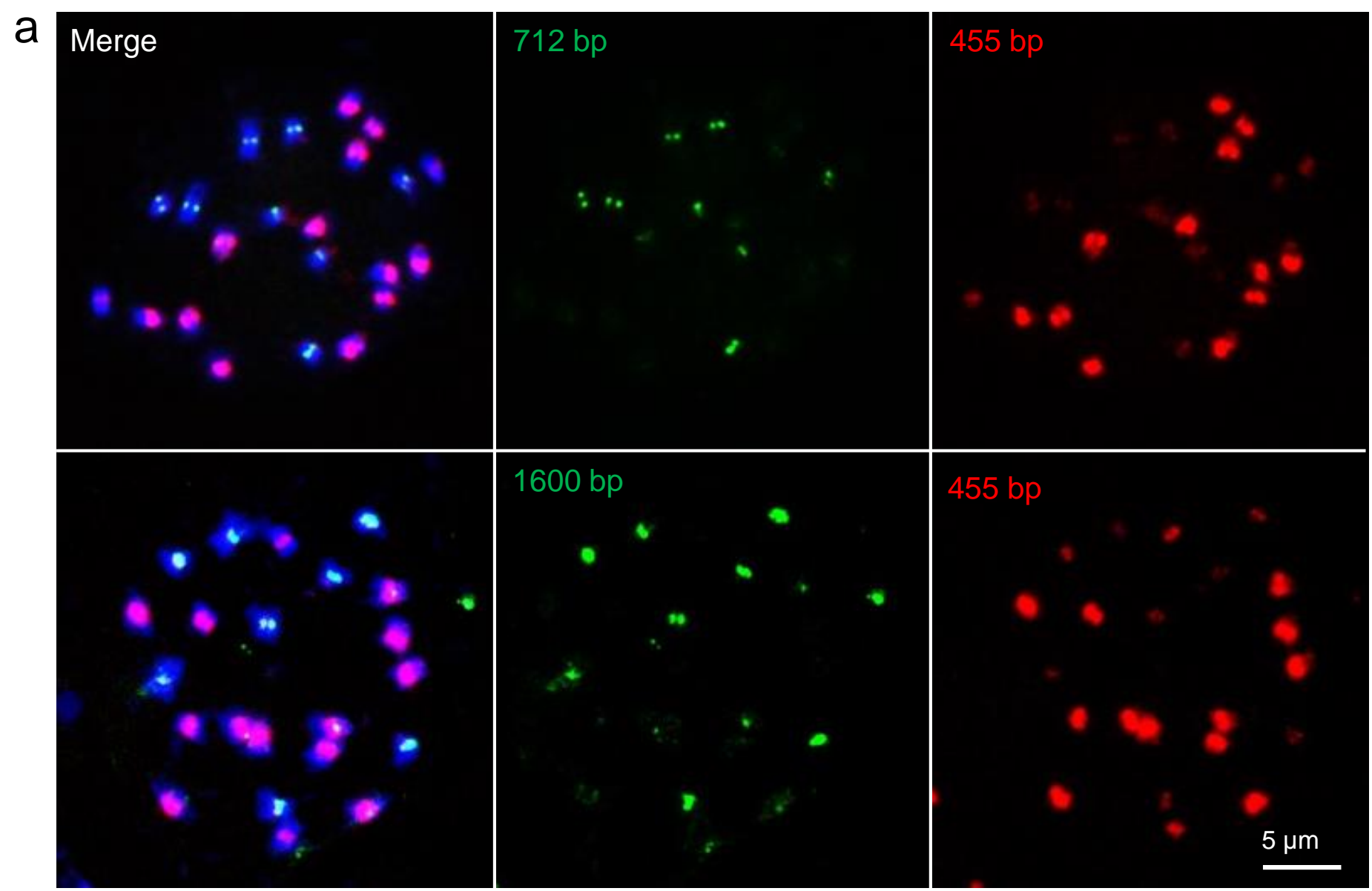

b

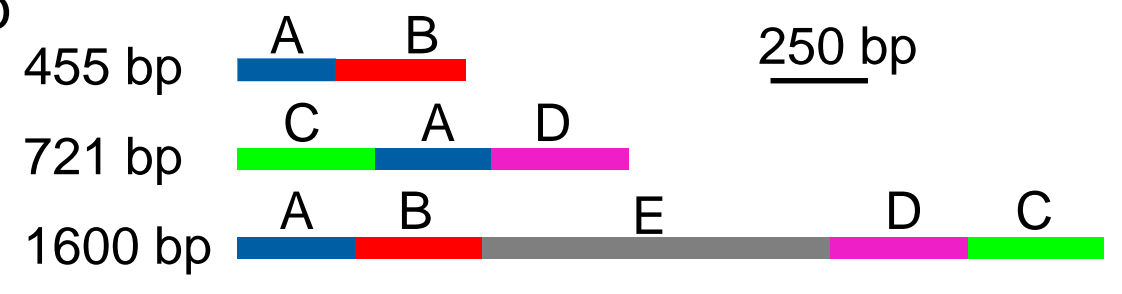

60 - 68\% AT rich sequences

Each color represents a

similar subrepeat (similarity $\sim 85 \%$ ).

C

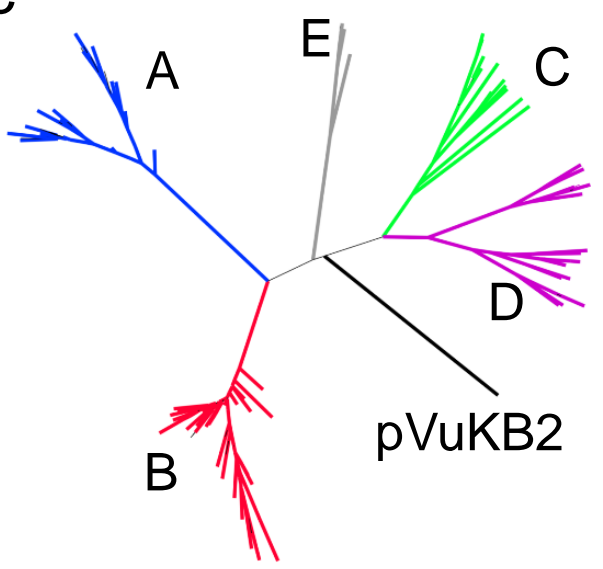


Fig. 8

(which was not certified by peer review) is the author/funder. All rights reserved. No reuse allowed without permission.

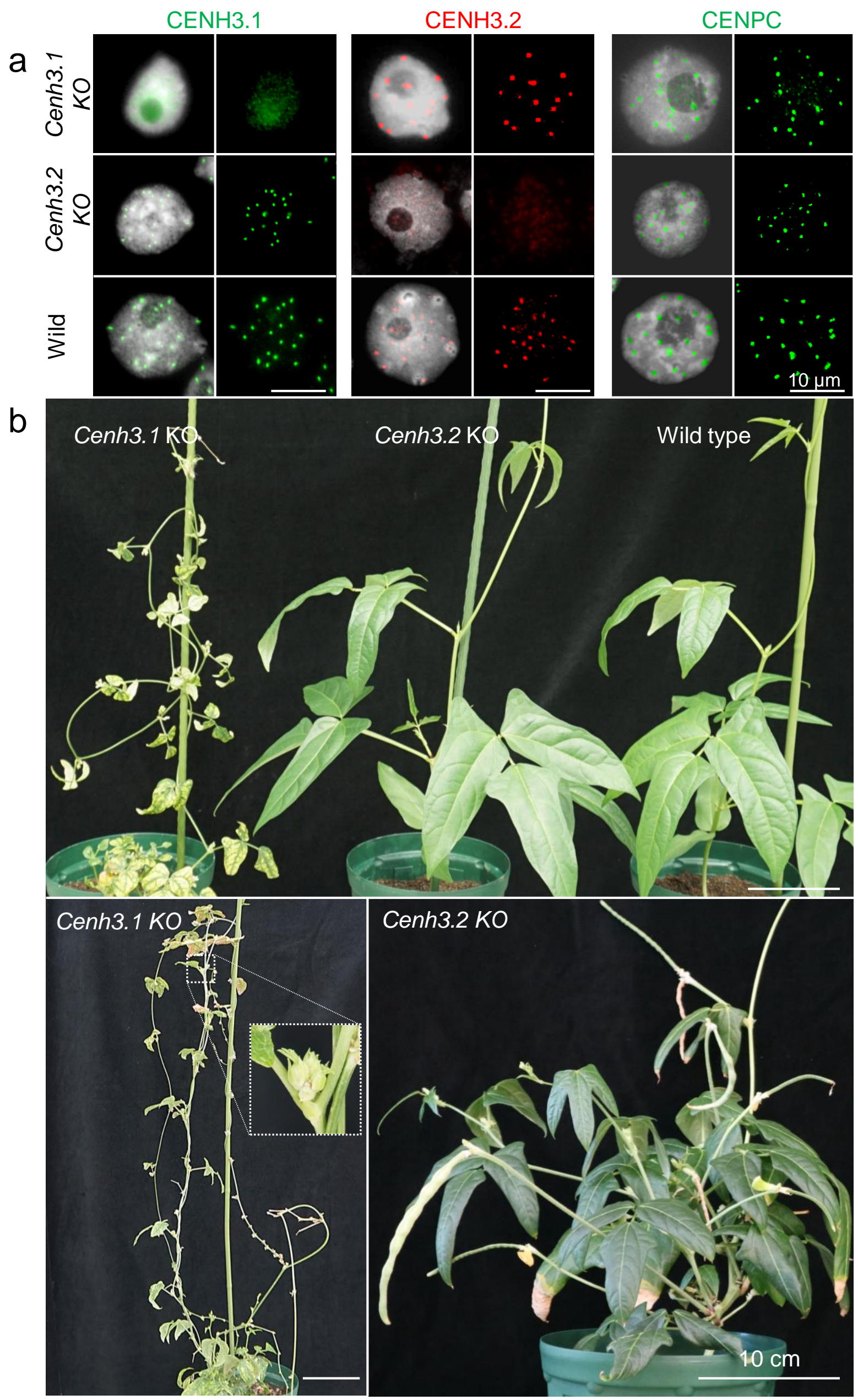




\section{- Suppl. Figures}


C (which was not certified by peer review) is the author/funder. All rights reserved. No reuse allowed without permission.

a

VUCENH3.1

VUCENH3.2

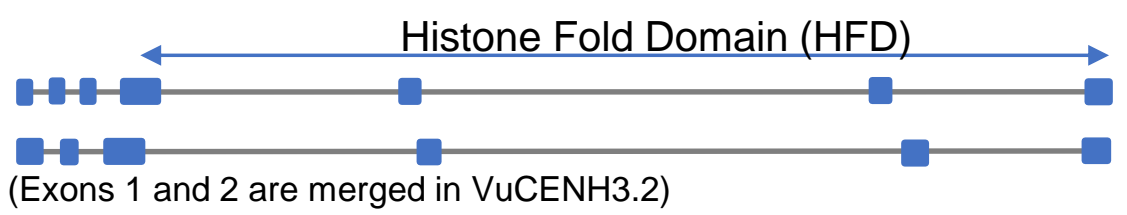

VuCENH3.3-pseudo (Exons 2, 3 and 4 only in VuCENH3.3-pseudo)

VuCENH3.4-pseudo

(Exons 5, 6, 7 only in VuCENH3.4-pseudo)

: Exon - : Intron $500 \mathrm{bp}$

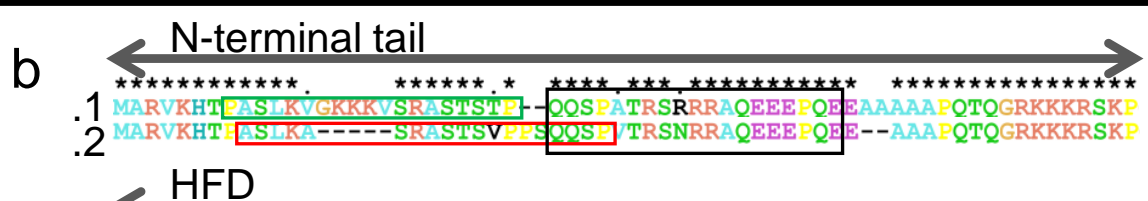

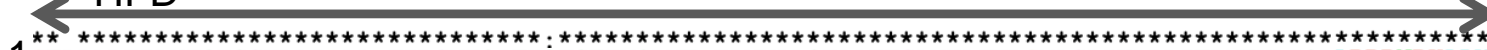

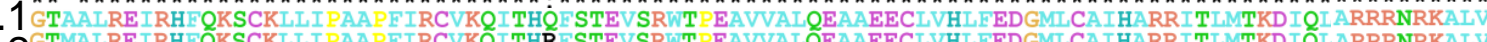

.2 GTMAREIRHFQKSCKLLIPAAPFIRCVKQ́ITHR STEVSRWT EAVVALQEAAEECLVHLED GMLCAIHARRITLMTKDIQLLARRRNRKALV

C Western blot analysis

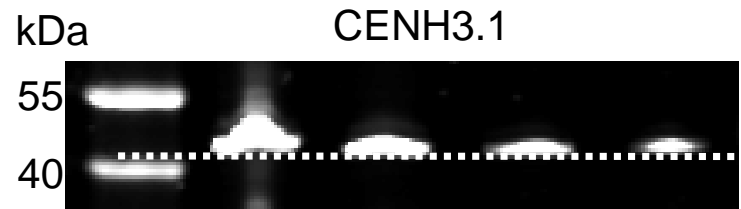

kDa $\quad$ CENH3.2
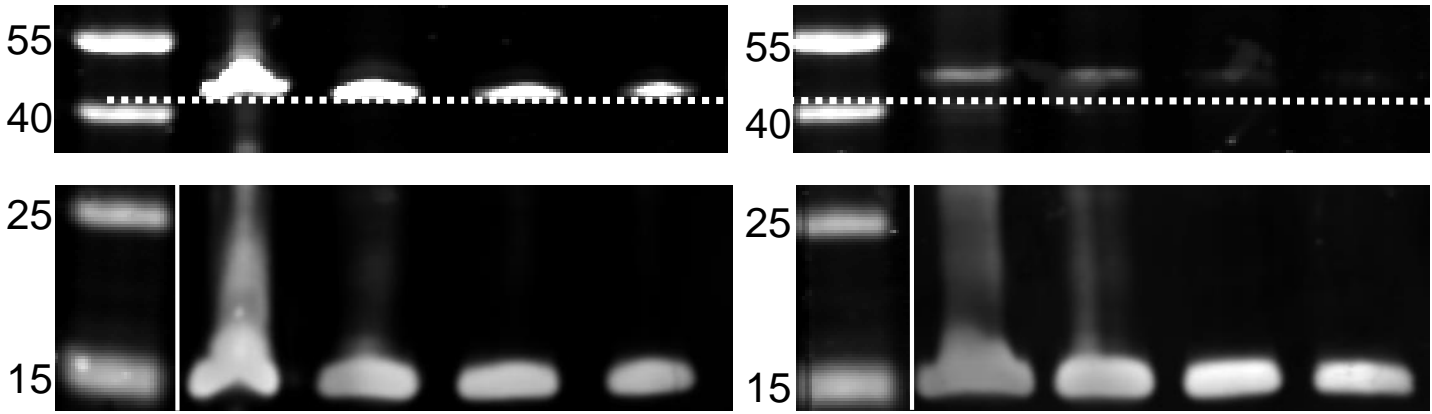

CENH3 dimer
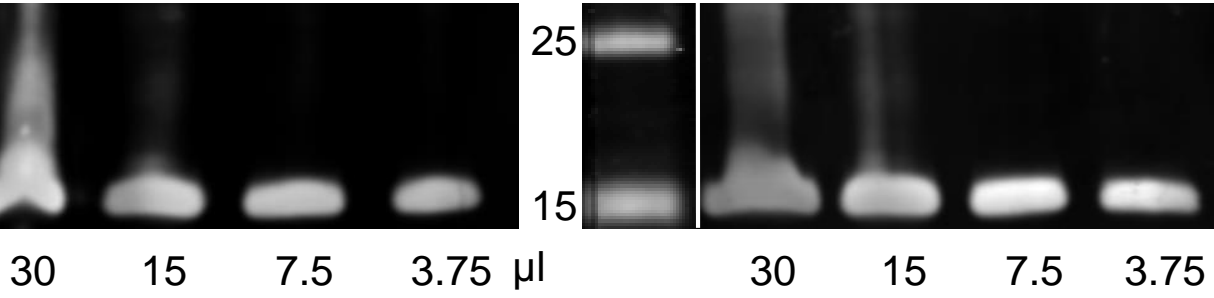

$4 \mathrm{H} 3$

$\begin{array}{llll}30 & 15 & 7.5 & 3.75 \mu l\end{array}$


Supp. Fig. 2

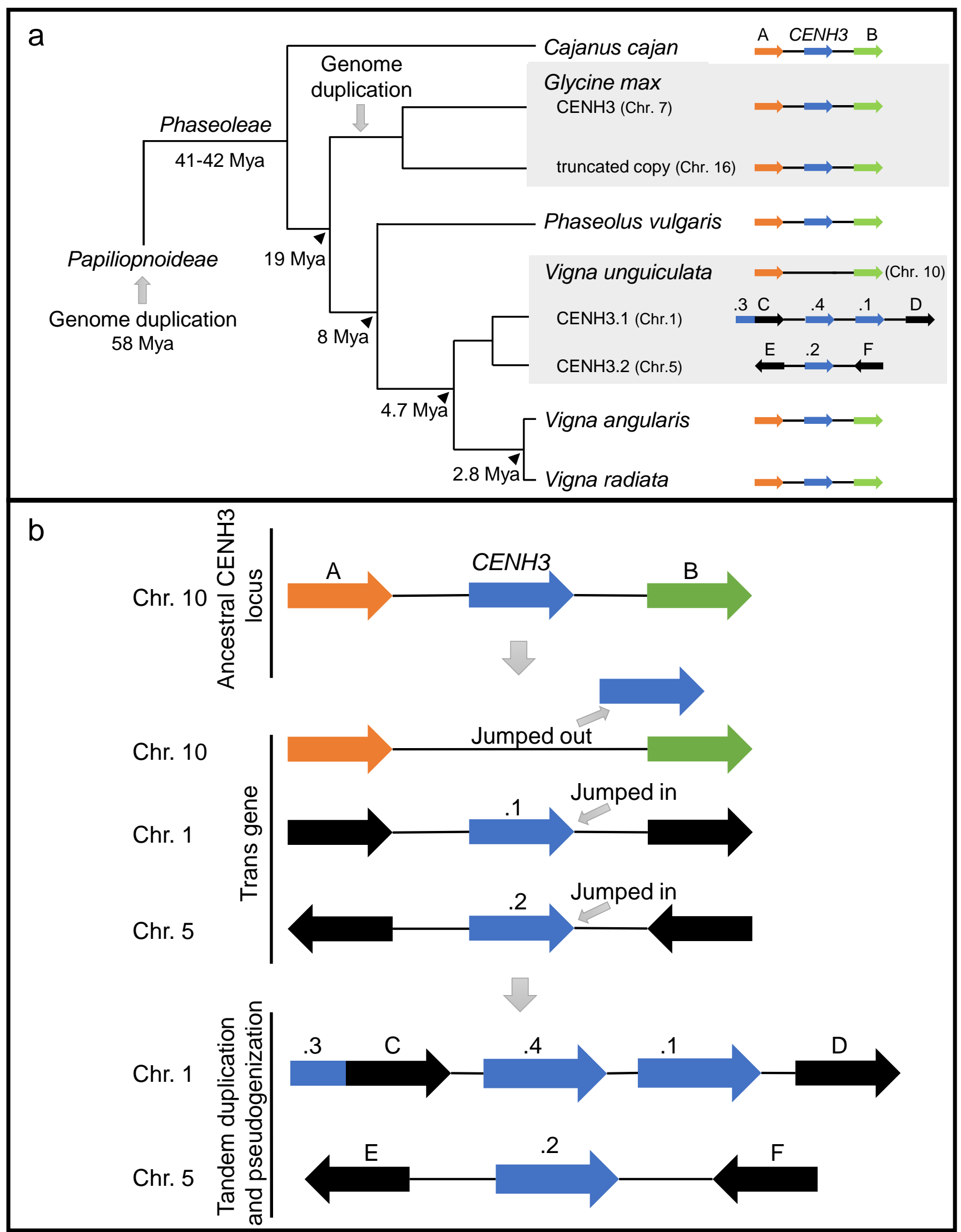




\section{Suppl. Fig 3}

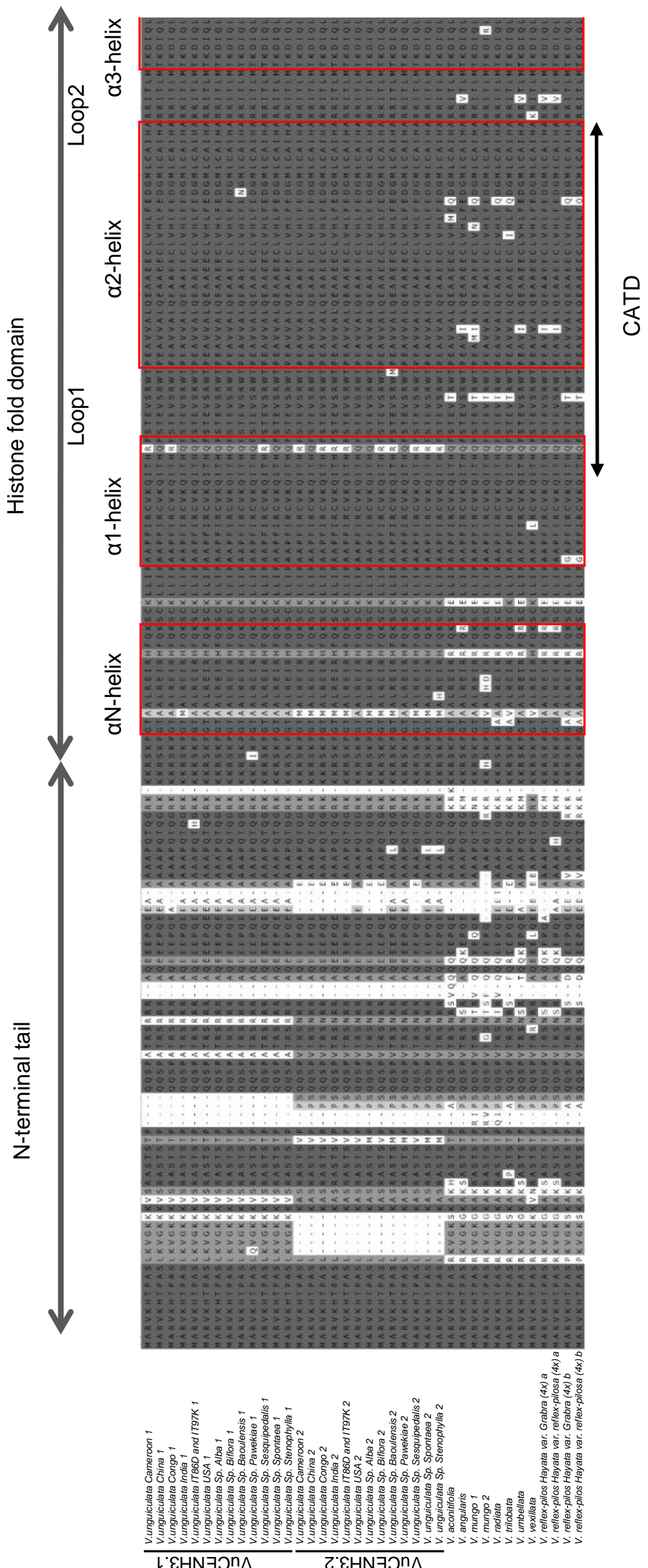


(which was not certified by peer review) is the author/funder. All rights reserved. No reuse allowed without permission.

Supp. Fig. 4

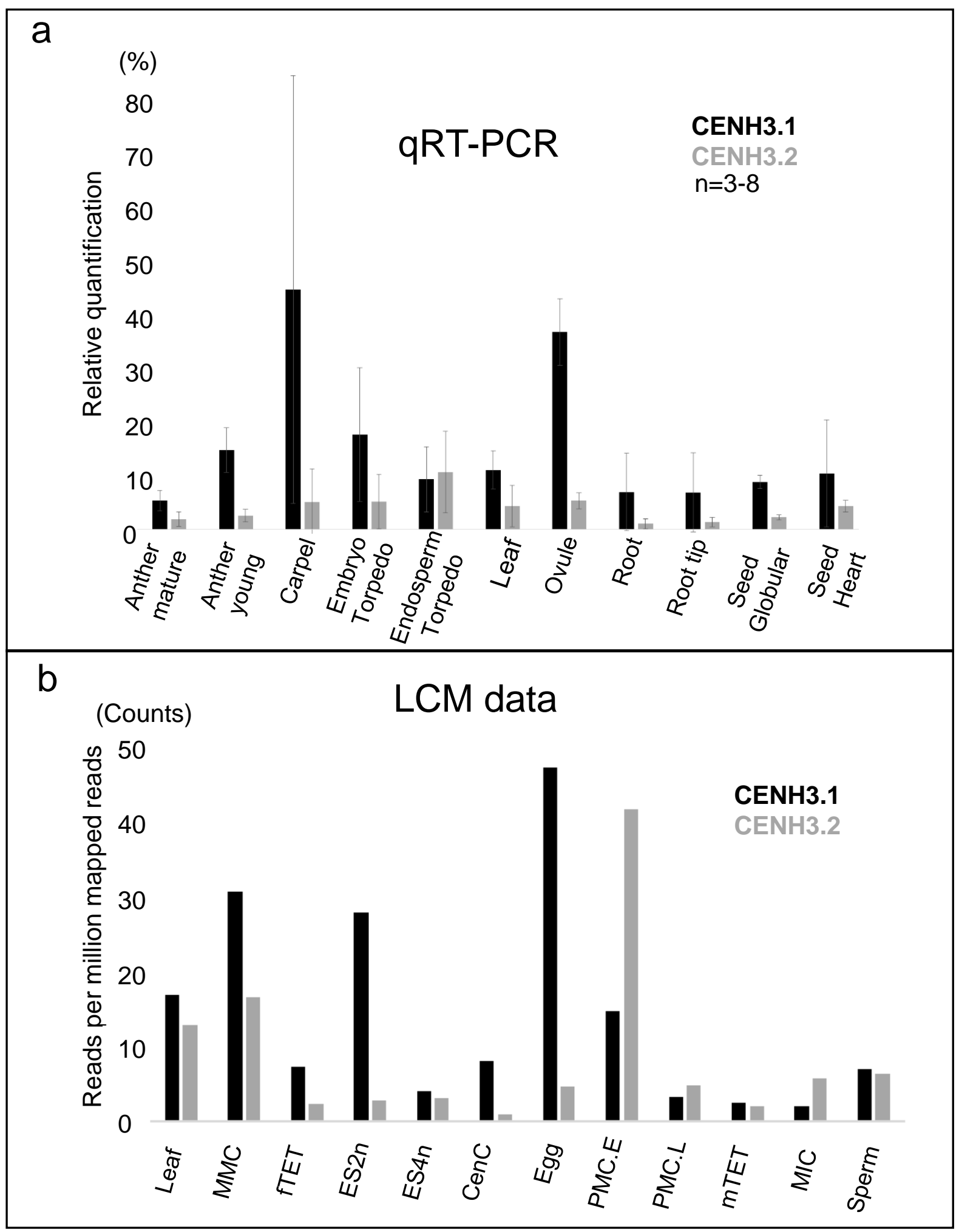


Supp. Fig. 5

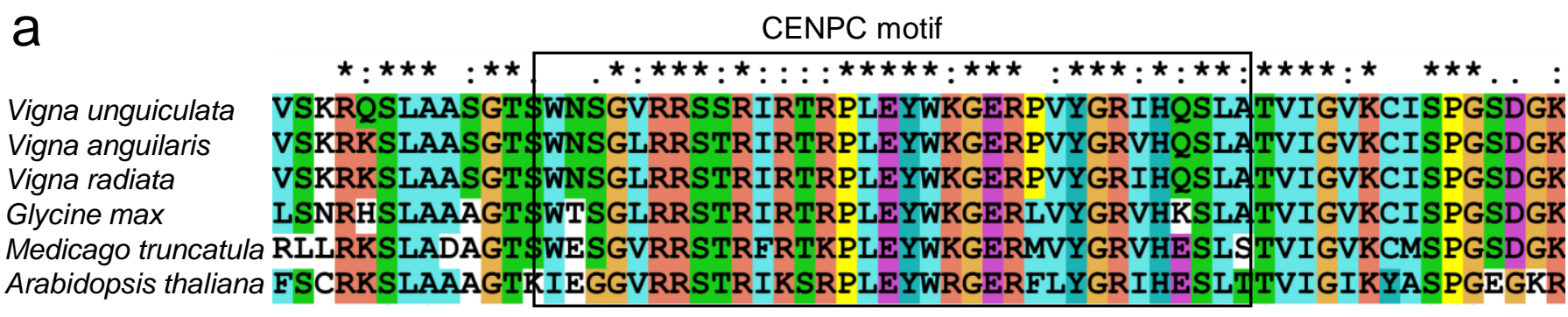

b

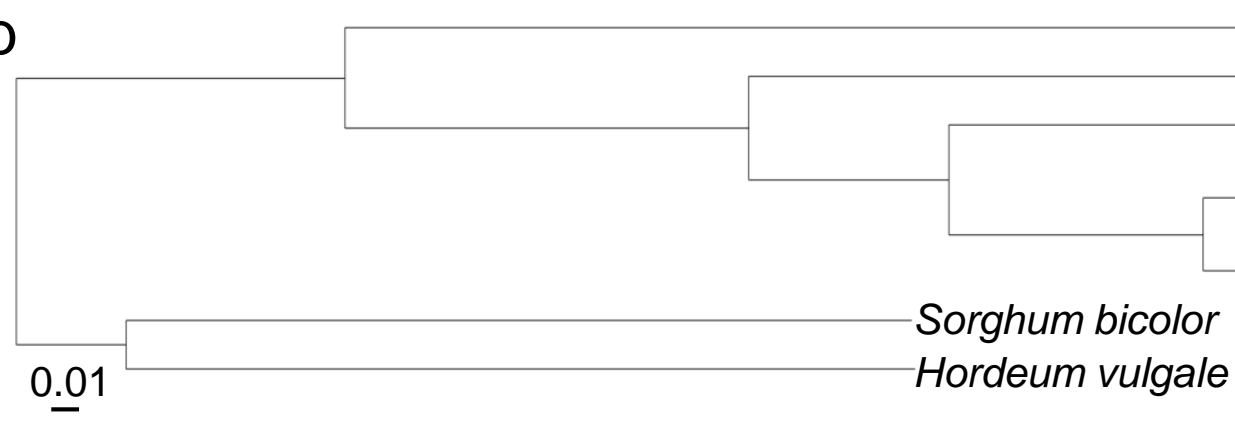

Arabidopsis thaliana - Medicago truncatula Glycine max

Vigna radiata

Vigna angularis

Vigna unguiculata Hordeum vulgale 


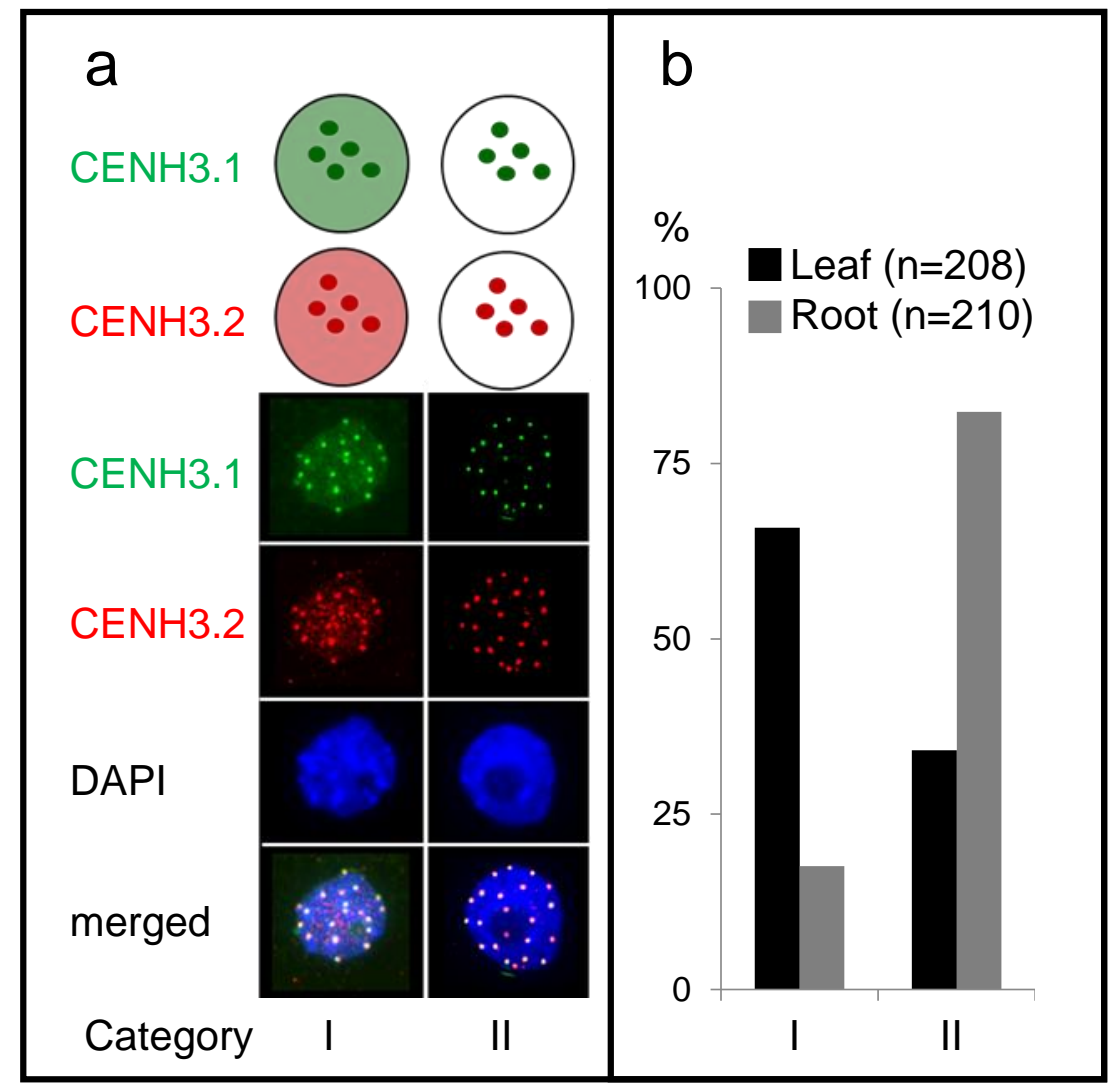


C (which was not certified by peer review) is the author/funder. All rights reserved. No reuse allowed without permission.

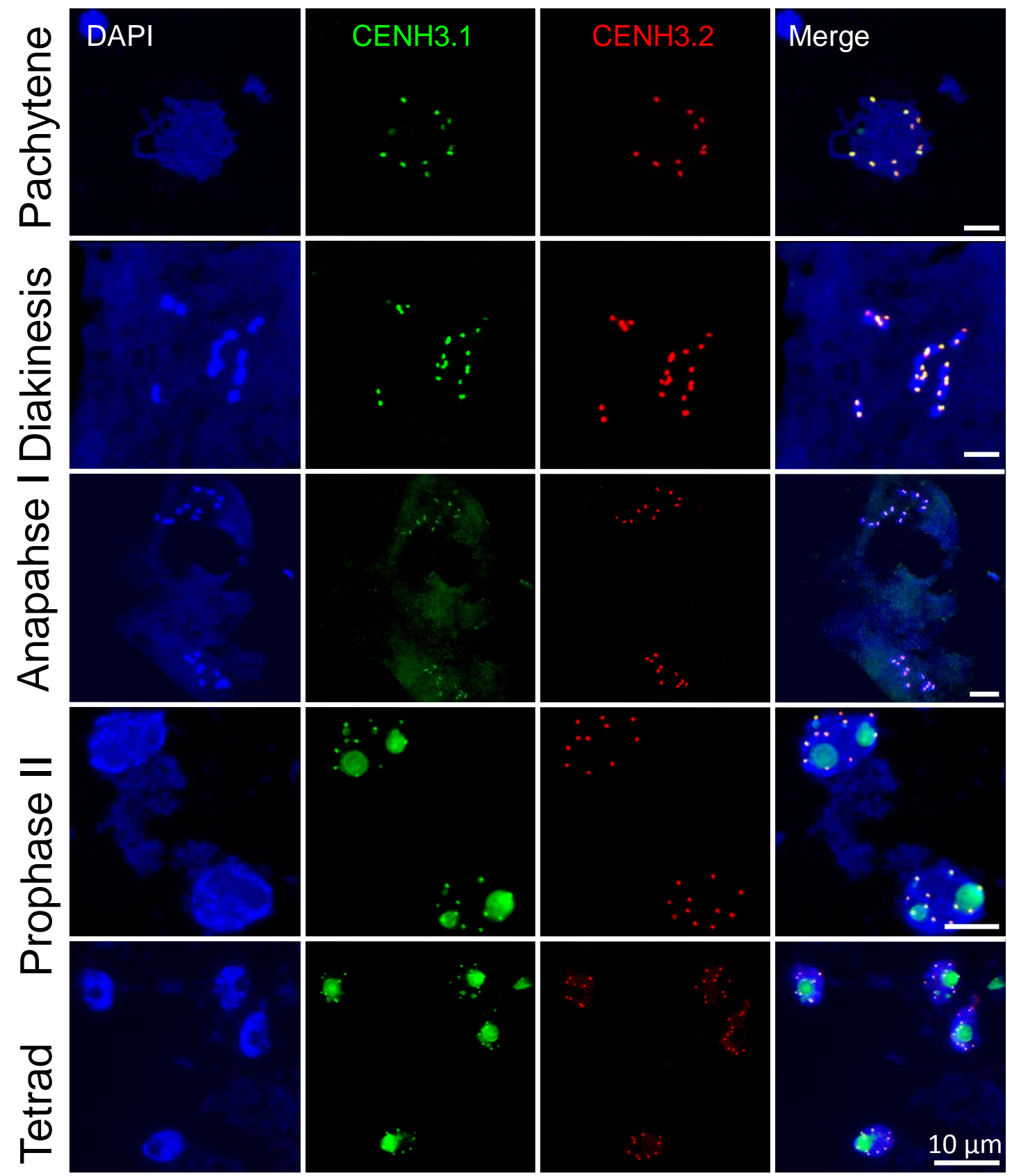




\section{(which was not certified by peer review) is the author/funder. All rights reserved. No reuse allowed without permission.}

Supp. Fig 8

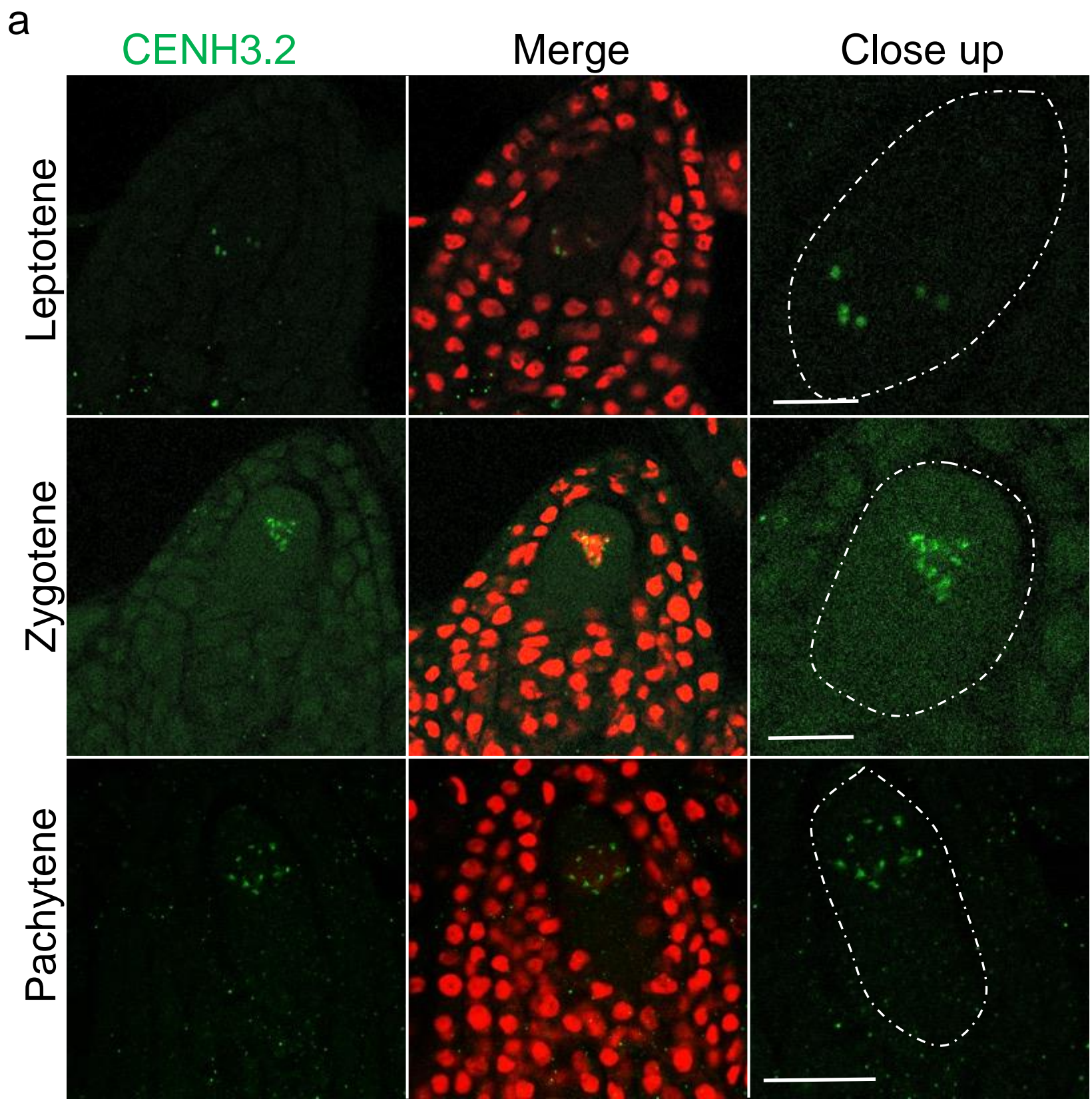

b

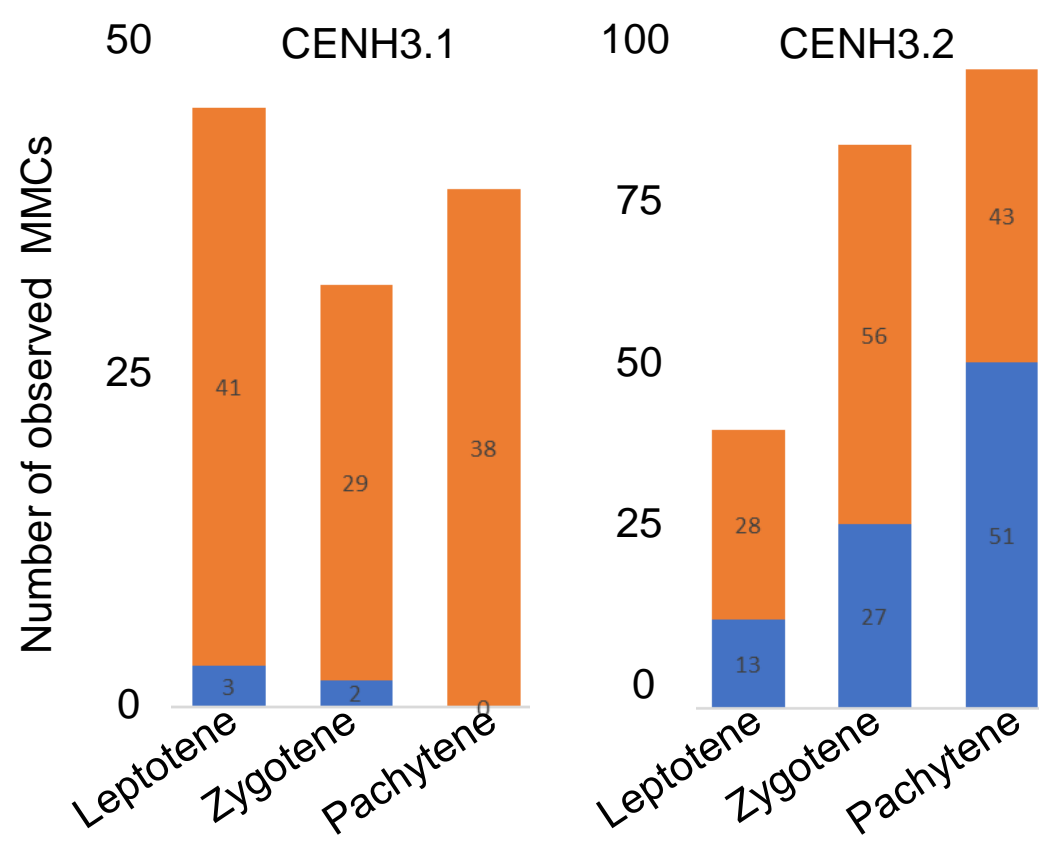

detectable signals not detectable 
Supp. Fig. 9

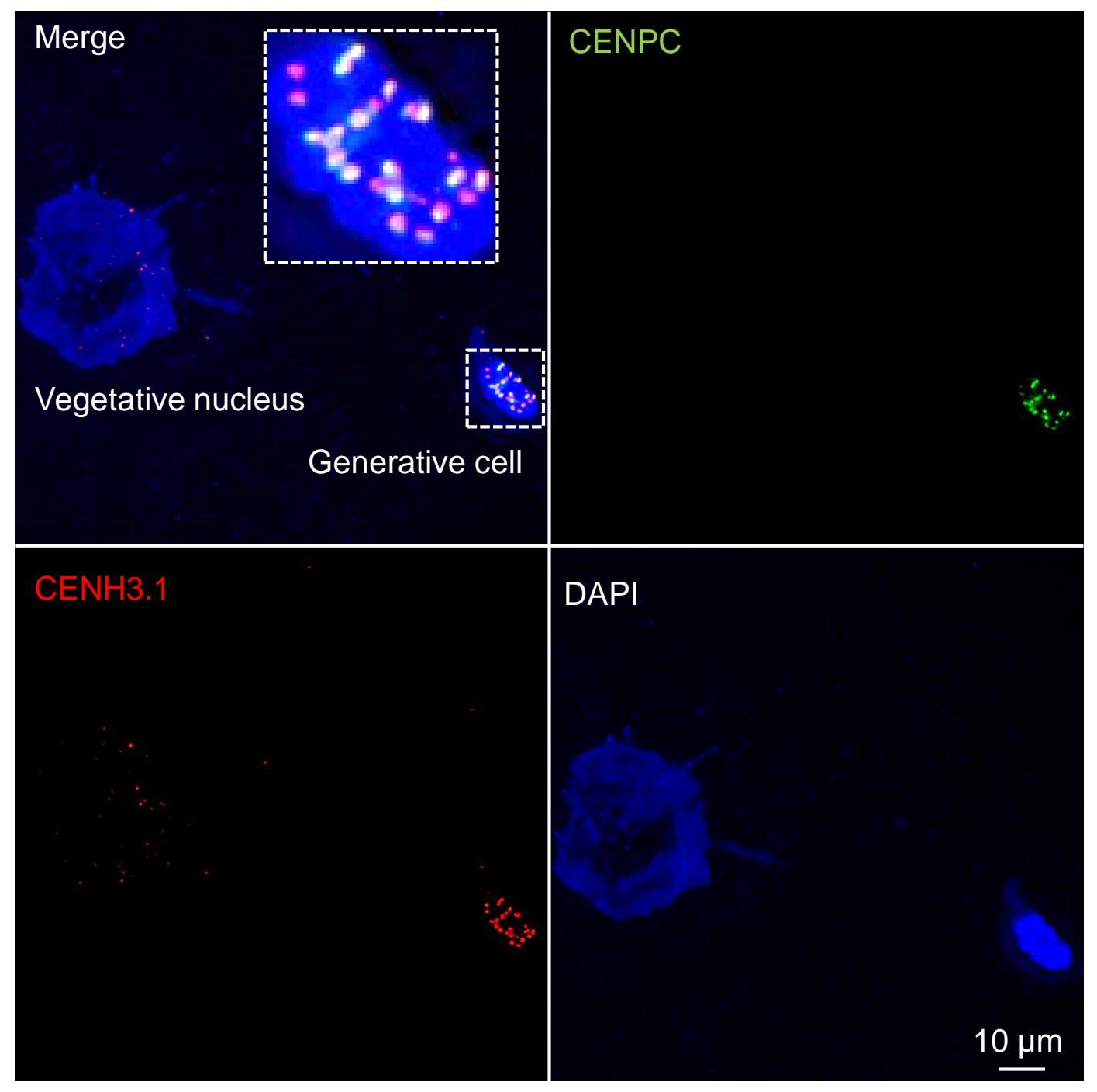


Supp. Fig. 10
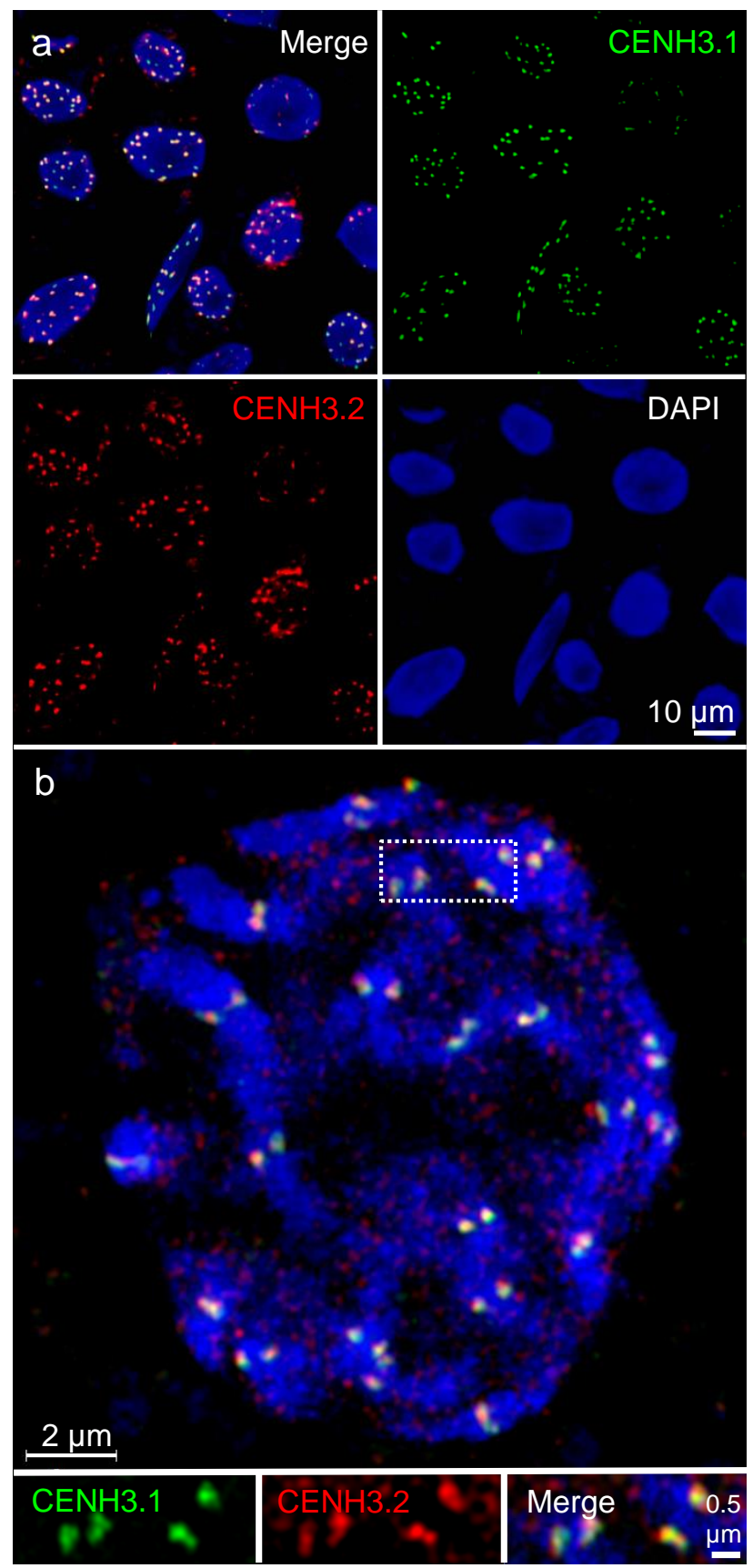